\title{
Similarity Solutions of Unsteady Mixed Convective Boundary Layer Flow of Viscous Incompressible Fluid along Isothermal Horizontal Plate
}

\author{
Mohammed Nasir Uddin"1, Md. Yeakub Ali1 ${ }^{*}$, N. M. Ridwan Zahed1 ${ }^{1}$, Md. Jashim Uddin ${ }^{1,2}$ \\ ${ }^{1}$ Department of Mathematics, Chittagong University of Engineering \& Technology, Chittagong, Bangladesh \\ ${ }^{2}$ Department of Electrical \& Electronic Engineering, International Islamic University Chittagong, Chittagong, Bangladesh \\ Email: *ali69cuet@gmail.com
}

How to cite this paper: Uddin, M.N., Ali, Md.Y., Zahed, N.M.R. and Uddin, Md.J. (2016) Similarity Solutions of Unsteady Mixed Convective Boundary Layer Flow of Viscous Incompressible Fluid along Isothermal Horizontal Plate. Open Journal ot Fluid Dynamics, 6, 279-302.

http://dx.doi.org/10.4236/ojfd.2016.64022

Received: September 1, 2016

Accepted: November 26, 2016

Published: November 29, 2016

Copyright $\odot 2016$ by authors and Scientific Research Publishing Inc. This work is licensed under the Creative Commons Attribution International License (CC BY 4.0).

http://creativecommons.org/licenses/by/4.0/

\begin{abstract}
Unsteady mixed convective boundary layer flow of viscous incompressible fluid along isothermal horizontal plate is analyzed through Similarity Solutions. The governing partial differential equations are transformed into ordinary differential equations using the similarity transformation and solved numerically along with shooting technique. The flow field for the fluid velocity, temperature and concentration at the plate surface are significantly influenced by the governing parameters such as unsteadiness parameter, permeability parameter, Prandtl number, Schmidt number and the other driving parameters. The results show that both fluid velocity and temperature decrease but no significant effect on concentration for the increasing values of Prandtl number. It is also exposed that velocity and concentration is higher at lower Schmidt number for low Prandtl fluid. Finally, the dependency of the Skin-friction co-efficient, Nusselt number and Sherwood number, which are of physical interest, are also illustrated in tabular form for the governing parameters.
\end{abstract}

\section{Keywords}

Similarity Solution, Unsteady Flow, Mixed Convection, Boundary Layer Flow, Horizontal Plate, Incompressible Fluid

\section{Introduction}

The study of mixed convective boundary layer flows is generated much in many engineering processes and also in polymer industries for fiber-glass production and condensation process. This study is very practical and worthy enough to discuss perfectly. If the fluid flow is caused solely due to the density differences resulting from temperature 
gradients without assistance of external force like a pump or a fan is termed as natural or free convection flow. Such flow is generated due to the buoyancy effects which is observed in many heat transfer processes and is applied in many technological applications. A convection situation involving both free and forced convection is known as mixed convection. In mixed convection flows, the forced and free convection effects are of comparable magnitude. Many studies exist for the mixed convection boundary layer flow about vertical, inclined, horizontal and wedge surfaces immersed in a viscous fluid. Because of significant effects of buoyancy on the flow field pressure gradient changes through the depth of the layer. Former researchers verified the effect of buoyancy and they focused on flows over plates which are smoothly cooled or heated.

K. Stewartson [1] earlier considered the theory of laminar boundary layers in compressible fluid and analyzed also for the laminar two-dimensional boundary layer flow on a semi-infinite horizontal plate. L. J. Crane [2] was the first who reported the analytical solution for the laminar boundary layer flow past a stretching sheet. After this pioneering work, P. S. Gupta and A. S. Gupta [3] added new dimension to the study with suction and injection. Johnson and Cheng [4] examined the necessary and sufficient conditions under which similarity solution exist for free convection boundary layers adjacent to flat plates in porous media. N. Afzal and T. Hussain [5] studied mixed convection over a horizontal plate.

Kumari et al. [6] observed that the unsteadiness in the flow field was caused by the time dependent velocity of the moving sheet. The constant temperature and the constant heat flux conditions were consideration in their investigation. Slaouti et al. [7] investigated that the temperature and surface heat transfer were changed in a small interval of time for the unsteady free convection flow in the stagnation-point region of a three dimensional body. Pierre-Yves Lagree [8] studied removing the marching breakdown of the boundary-layer equations for mixed convection above a horizontal plate. This study is very interesting because it summarizes all the difficulties of boundary layer flows. J. Kim, Y. T. Kang and C. K. Choi [9] analyzed convective instability and heat transfer characteristics of nanofluids. A. J. Chamkha and A. Al-Mudhaf [10] examined unsteady heat and mass transfer from a rotating vertical cone with a magnetic field and heat generation or absorption effects. O. Aydin and A. Kaya [11] performed an analysis for the laminar boundary layer flow over a porous horizontal flat plate, particularly, to study the effect of uniform suction or injection on the heat transfer. Using the constant surface temperature as thermal boundary condition, they also investigated the effect of Prandtl number on heat transfer. M. E. Ali and E. Magyari [12] studied unsteady fluid and heat flow induced by a submerged stretching surface while its steady motion is slowed down gradually. Ali M. Yeakub and Hossain M. M. Touhid [13] reported the analytical similarity solutions for unsteady laminar Natural convection boundary layer flow around a vertical heated curvilinear surface.

K. Vajravelu, K. V. Prasad and Chu [14] studied unsteady mixed convective boundary layer flow of a viscous fluid at a vertical surface with variable fluid properties. G. Singh and P. R. Sharma [15] analyzed heat and mass transfer in the boundary layer flow 
along a vertical isothermal reactive plate near stagnation point.

Recently, Ali et al. [16] [17] [18] studied similarity solutions of unsteady convective boundary layer flow along isothermal vertical plate with porous medium. Further we also investigated similarity solutions for an internal heat generation, thermal radiation and free convection unsteady boundary layer flow over a vertical plate. Moreover, we discussed unsteady laminar hydro-magnetic free convection boundary layer flow over semi-infinite and permeable inclined flat plates.

So far as we know, no previous study has been made to analyze unsteady mixed convective boundary layer flow along isothermal horizontal plate. In the present study, an attempt is made to investigate unsteady mixed convective boundary layer flow of viscous incompressible fluid along isothermal horizontal plate.

The partial differential equations for governing the flow are transformed into ordinary differential equations using the similarity transformation and solved numerically. We have investigated the effect of several governing parameter such as Reynolds number, Prandtl number, unsteadiness parameter, permeability parameter and buoyancy parameter and other flow parameters like Skin-friction co-efficient, Nusselt number and Sherwood number on the flow field. Furthermore the effect of suction has been taken into consideration. The governing differential equations relevant to the problem have been solved by using the similarity technique. Secondly computed numerical results were exhibited and analyzed in detail for different values of the involving parameters in the similarity transformation.

\section{Mathematical Formulation of the Problem}

We consider an unsteady two dimensional mixed convective boundary layer flow of a viscous incompressible fluid along horizontal isothermal plate. The plate surface generates inert specie which diffuses inside the boundary. The co-ordinate system is selected such that $\mathrm{x}$-axis is in the horizontal direction. The unsteady fluid flows start at time $t=$ 0 . The potential flow is given by the velocity distribution $U_{\infty}(x)=a$ and $V_{\infty}(y)=a y$, where " $a$ " is a positive constant. The velocity of the fluid far away from the plate surface is assumed to be zero. Here magnetic Reynolds number is assumed to be very small so induced magnetic dissipation is negligible. Using unsteady boundary layer approximation, the governing equations of such type of flow are given by;

$$
\begin{gathered}
\frac{\partial u}{\partial x}+\frac{\partial v}{\partial y}=0 \\
\frac{\partial u}{\partial t}+u \frac{\partial u}{\partial x}+v \frac{\partial u}{\partial y}=-\frac{\partial p}{\partial x}+\gamma \frac{\partial^{2} u}{\partial y^{2}}+g \beta\left(T-T_{\infty}\right)+g \beta^{*}\left(C-C_{\infty}\right)+U_{\infty} \frac{\mathrm{d} U_{\infty}}{\mathrm{d} x}-\frac{\gamma}{\tilde{\kappa}}\left(u-U_{\infty}\right) \\
0=-\frac{\partial p}{\partial y}+J T \\
\frac{\partial T}{\partial t}+u \frac{\partial T}{\partial x}+v \frac{\partial T}{\partial y}=\frac{\kappa}{\rho c_{p}} \frac{\partial^{2} T}{\partial y^{2}}
\end{gathered}
$$




$$
\frac{\partial C}{\partial t}+u \frac{\partial C}{\partial x}+v \frac{\partial C}{\partial y}=D \frac{\partial^{2} C}{\partial y^{2}}
$$

The boundary conditions are:

$$
\begin{aligned}
& y=0, u=0, v=0, T=T_{w}, C=C_{w} \\
& y=\infty, u \rightarrow U_{\infty}=a, T \rightarrow T_{\infty}, C \rightarrow C_{\infty}, p=p_{0}
\end{aligned}
$$

where $x$ and $y$ are the coordinates measured along the plate and normal to it. $u, v$ are the velocity components along the $x$ and $y$ axes. $v$ is the kinematics viscosity, $\rho$ is the density of the fluid, $g$ is the acceleration due to gravity, $\beta$ and $\beta^{*}$ are the thermal and concentration expansion co-efficient respectively, $C$ is the species concentration in the boundary layer, $C_{\infty}$ is the species concentration of the ambient fluid, $C_{p}$ is the specific heat, $D$ is the molecular diffusivity of the species concentration, $T$ is the temperature inside the boundary, $T_{\infty}$ is the temperature for away from the plate, $\tilde{\kappa}$ is the permeability of the porous medium. The remaining parameter $J$ is the Richardson Number or buoyancy parameter, which depends on $\alpha$, thermal coefficient of expansion of the density in the Boussinesq approximation. The transverse pressure term contains the gravity term such as Equation (3). In order to simplify the mathematical analysis of the problem we introduce the stream function $\Psi(x, y)$ such that $u=\frac{\partial \psi}{\partial x}$ and $v=-\frac{\partial \psi}{\partial y}$, Where, $\Psi=\sqrt{a v} x t f$, and dimensionless variable,

$$
\eta=y \sqrt{\frac{a}{v}} \frac{1}{x t}, x=\xi, t=\tau \text { and } u=a f^{\prime}
$$

$\phi \quad($ Dimensionless concentration $)=\frac{C-C_{\infty}}{C_{w}-C_{\infty}}$

$\theta$ (Dimensionless temperature $)=\frac{T-T_{\infty}}{T_{w}-T_{\infty}}$

Introducing dimensionless similarity variables into the system of Equations (2)-(5) is reduced to system of ordinary differential equations;

$$
\begin{gathered}
f^{\prime \prime \prime}+A_{1} f f^{\prime \prime}+A_{2} \eta f^{\prime \prime}+J_{a} \eta^{2} \theta^{\prime}+G_{r} \theta+G_{c} \varphi-a_{3} K\left(f^{\prime}-1\right)=0 \\
\theta^{\prime \prime}+P_{r}\left(A_{1} f+A_{2} \eta\right) \theta^{\prime}=0
\end{gathered}
$$

and

$$
\phi^{\prime \prime}+S_{c}\left(A_{1} f+A_{2} \eta\right) \phi^{\prime}=0
$$

It is observed that the Equation (1) is identically same. The Boundary conditions in Equation (6) are reduced to the corresponding boundary condition for velocity, temperature and concentration fields are as;

$$
\begin{aligned}
& f(0)=0, f^{\prime}(0)=0, \theta(0)=1, \phi(0)=1 \text { at } \eta=0 \\
& f^{\prime}(\infty)=1, \theta(\infty)=0, \phi(\infty)=0 \text { at } \eta=\infty .
\end{aligned}
$$

where,

$$
G_{r} \quad(\text { Local Temperature Grashof number })=\frac{g \beta \xi^{2} \tau^{2}}{a^{2}}\left(T_{w}-T_{\infty}\right),
$$




$$
\begin{aligned}
& G_{c} \text { (Local Concentration Grashof number) }=\frac{g \beta^{*} \xi^{2} \tau^{2}}{a^{2}}\left(C_{w}-C_{\infty}\right), \\
& \left.J_{a} \quad \text { (Modified buoyancy parameter }\right)=\frac{J \xi^{2} \tau^{2} \sqrt{v}}{a^{\frac{5}{2}}}\left(T_{w}-T_{\infty}\right) \\
& K \quad \text { (Permeability parameter) }=\frac{\xi^{2} \tau^{2} v}{a \tilde{\kappa}}, \\
& \left.S_{c} \quad \text { (Schomidt number }\right)=\frac{v}{D}, \\
& P_{r} \quad \text { (Prandtl number) }=\frac{\mu c_{p}}{\kappa} \text { and } \\
& \text { Unsteadiness parameters } A_{1}=\xi \tau^{2}, A_{2}=\frac{\xi^{2} \tau}{a} .
\end{aligned}
$$

The above equations with boundary condition are solved numerically by using shooting method. The effect of various governing parameters on the fluid velocity, temperature, pressure, concentration is exhibited in Figures. Finally, the dependency of the Skin-friction co-efficient, Nusselt number and Sherwood number, which are of physical interest are also illustrated in tabular form and analyzed in details.

\section{Important Physical Parameters}

Skin-friction co-efficient at the plate is defined as

$$
C_{f}=\frac{\tau_{w}}{\rho U_{w}^{2} / 2}=2(R e)^{-1 / 2} f^{\prime \prime}(0),
$$

The rate of heat transfer in terms of Nusselt number at the plate is given by

$$
N u_{x}=\frac{x q_{w}}{k \Delta T}=-(R e)^{1 / 2} \theta^{\prime}(0),
$$

The ratio of mass transfer in terms of the Sherwood number at the plate is given by

$$
S_{h_{x}}=\frac{x m_{w}}{D \Delta C}=-(R e)^{-1 / 2} \phi^{\prime}(0)
$$

where, the wall shear stress $\tau_{w}$, the wall heat flux $q_{w}$ and the quantity of mass transfer $m_{w}$ through the unit area of the surface. These are given by

$$
\tau_{w}=\mu\left(\frac{\partial u}{\partial y}\right)_{y=0} ; q_{w}=k\left(\frac{\partial T}{\partial y}\right)_{y=0}, m_{w}=D\left(\frac{\partial C}{\partial y}\right)_{y=0}
$$

Thus the values of the local skin-friction co-efficient $C_{f_{x}}$, local Nusselt number $N u_{x}$ and local Sherwood number $S_{h_{x}}$ are proportional to $f^{\prime \prime}(0),-\theta^{\prime}(0)$ and $\phi^{\prime}(0)$ respectively along with K. Vajravelu et al. [14].

\section{Numerical Solution}

The obtained systems of non-linear ordinary differential equations together with boundary conditions are transformed into simultaneous linear differential equations of first order and then solved numerically by applying the Shooting method namely Nachtsheim-Swigert (1965) iteration technique (guessing the missing value) along with 
Runge-Kutta integration scheme. Nachtsheim-Swigert iteration technique is used as the main tool for the numerical approach. The dimensionless similarity equations for momentum, temperature and concentration equations are solved numerically by this iteration technique. In shooting method, the missing (unspecified) initial condition at the initial point of the interval is assumed and the differential equation is also integrated numerically as an initial value problem to the terminal point. The accuracy of the assumed missing initial condition is then checked by comparing the calculated value of the dependent variable at the terminal point with its given value. If a difference exists, another value of the missing initial condition must be assumed thus the process is repeated. This process is continued until the agreement between the calculated and the given condition for the specified degree of accuracy. In the process of iteration, the Skin friction coefficient, the Nusselt number and the Sherwood number proportional to $f^{\prime \prime}(0),-\theta^{\prime}(0)$ and $\phi^{\prime}(0)$ respectively are also evaluated.

\section{Results and Discussions}

Numerical computations are executed for several values of dimensionless parameters involved in the equations controlling the fluid dynamics in the flow regime. The values of the Prandtl number, $P r=0.71,01.00$ and 07.00 correspond to air, electrolyte solution such as salt water and fresh water at $25^{\circ} \mathrm{C}$ and $1 \mathrm{~atm}$ pressure. The values of Schmidt number, $S c=00.22,00.62$ and 02.62 represent diffusing chemical species of most common interest in air like hydrogen, water vapor, and Propel Benzene respectively at $25^{\circ} \mathrm{C}$ and 1 atm pressure. The values of suction parameter, is considered to be 00.50 . Here, local temperature Grashof number $(G r)$ corresponds to the cooling problem for the cooling of electronic components and nuclear reactors in engineering applications. Local concentration Grashof number $(G c)$ indicates the chemical species concentration in the free stream region. The velocity $f^{\prime}$, temperature $\theta$, concentration $\phi$ are determined as a function of coordinate $\eta$.

\subsection{Velocity Profiles}

The variations of dimensionless velocity profiles in the boundary layer are depicted in Figures 1-8. Generally it is observed in the fluid velocity is lowest at the plate surface then increases quickly to its free stream values far away from the plate surface and leads to 1 with the increases of $\eta$ satisfying the boundary condition for all parameters. Figure 1 and Figure 2 demonstrate the influence of unsteadiness parameters $A_{1}$ and $A_{2}$ on the dimensionless velocity. We see that the velocity profile decrease with the increase of $A_{1}$ and $A_{2}$.

Figure 3 and Figure 4 represent the variation of the velocity profiles with the local temperature Grashof number, $G r$ and Local concentration Grashof number, $G c$. These Figs. show that velocity profile increase in both cases with the increase of $G r \& G c$. Thus it is established that increase in buoyancy forces enhance the fluid flow.

Figure 5 reveals the velocity profile for the selected values of permeability parameter $K$. It is found that velocity decreases gradually for increasing values of $K$. Due to the 


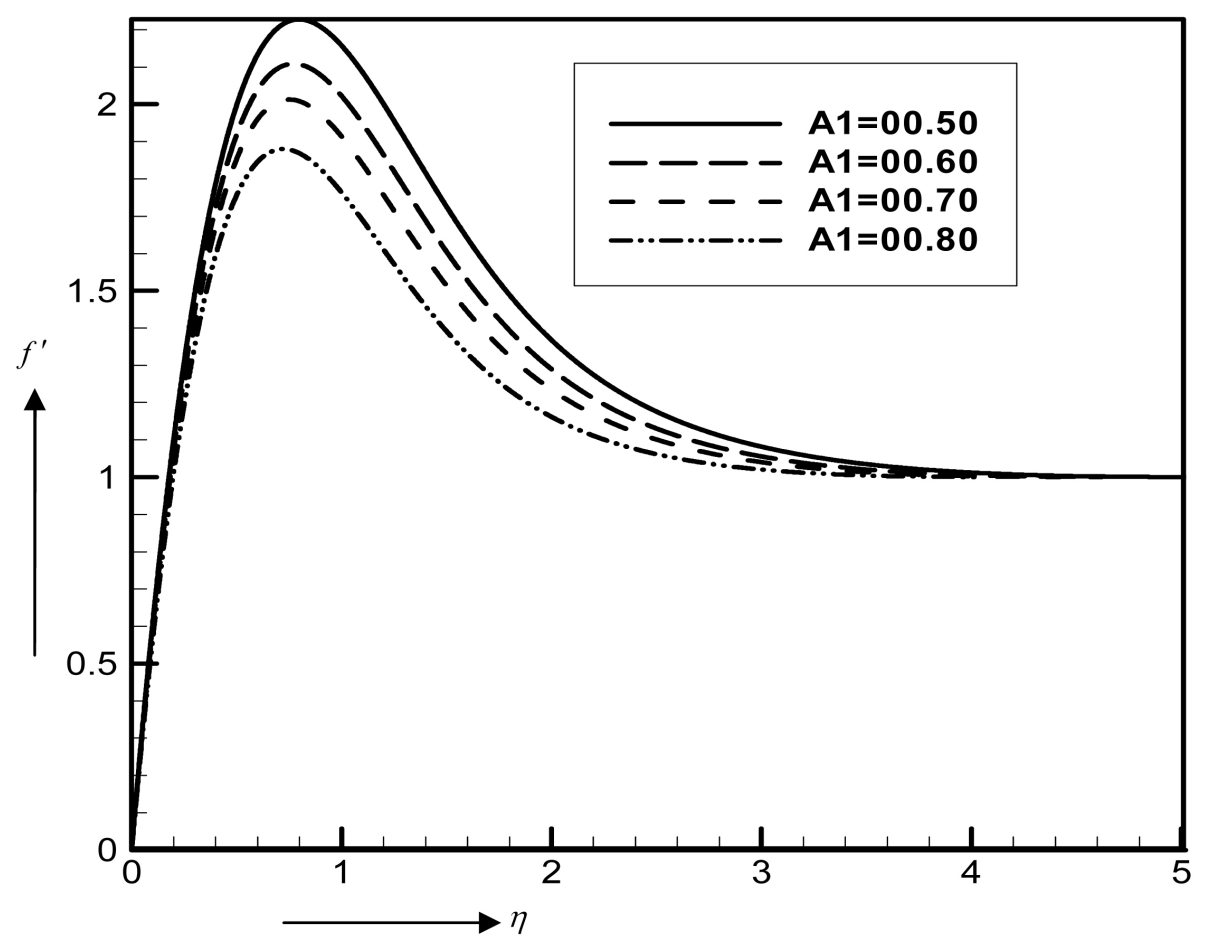

Figure 1. Velocity profile for various values of $A_{1}$ when, $A_{2}=0.50, \operatorname{Pr}=0.71, S c=0.22, G r=$ 05.0, $G c=05.00, K=00.60, J_{a}=01.00$.

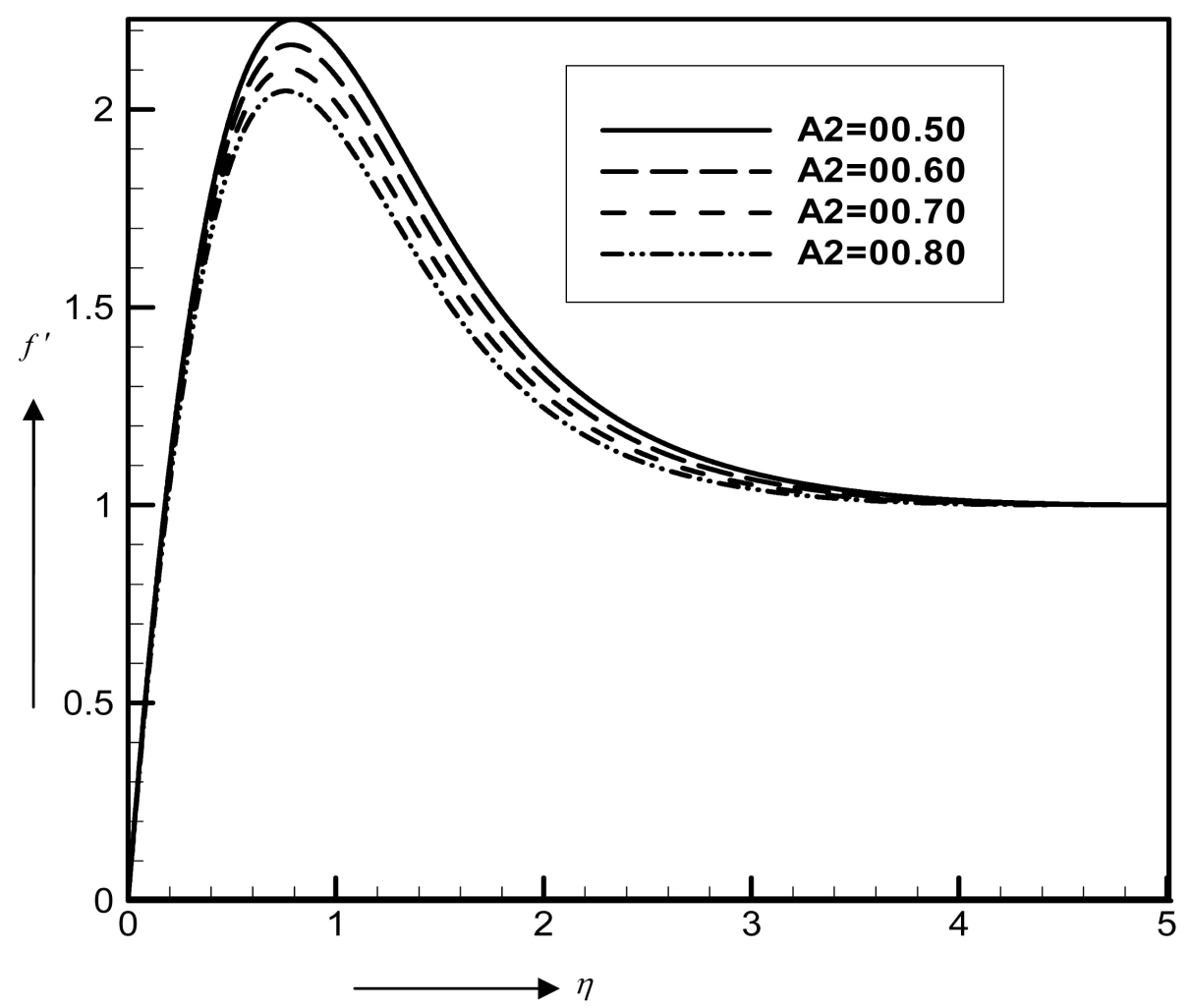

Figure 2. Velocity profile for various values of $A_{2}$. When, $A_{1}=0.50, \operatorname{Pr}=0.71, S c=0.22, G r=$ 5.00, $G c=5.00, K=0.60, J_{a}=01.00$. 


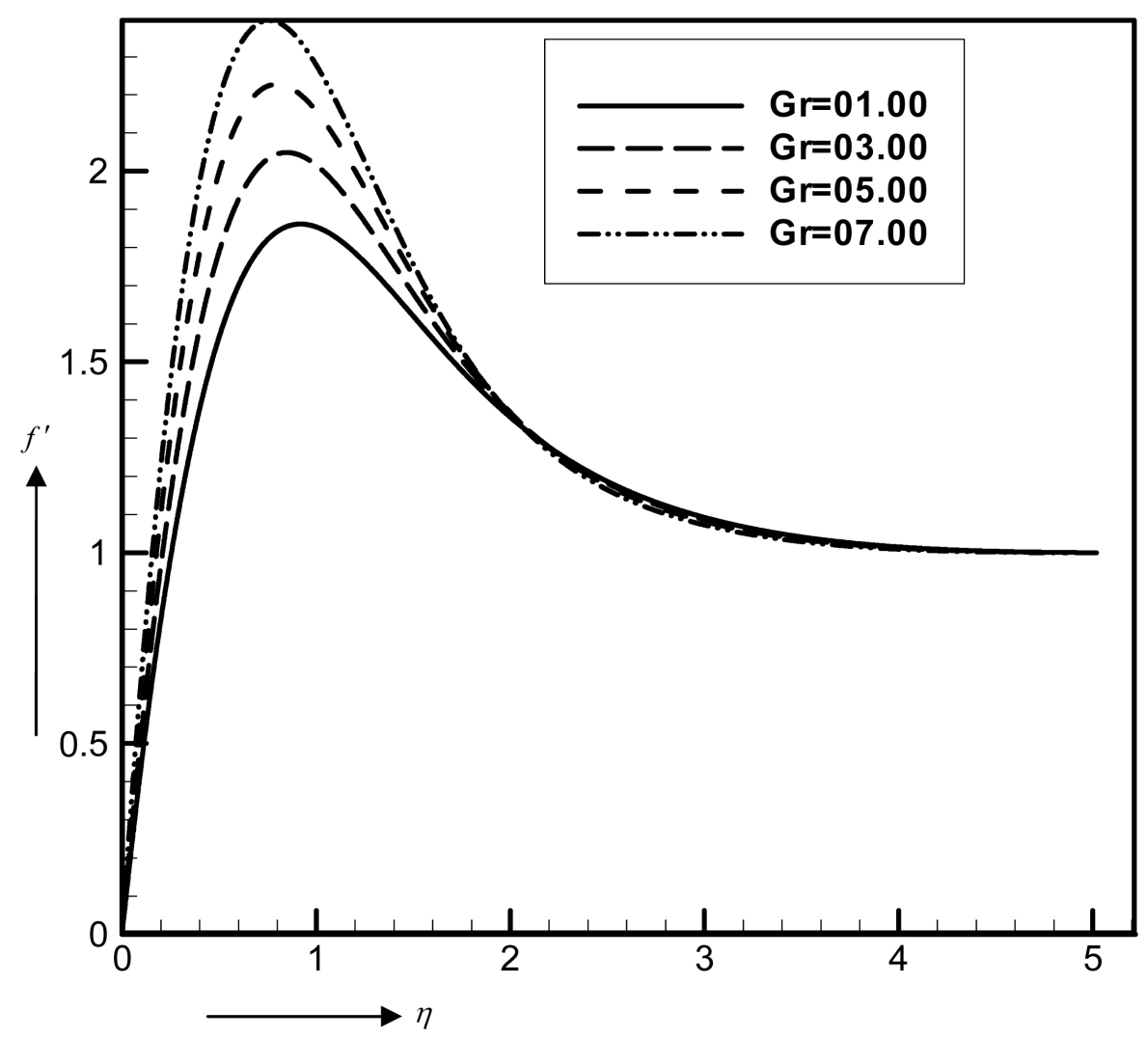

Figure 3. Velocity profile for various values of $G r$. when, $A_{1}=0.50, A_{2}=0.50, \operatorname{Pr}=0.71, S c=$ $00.22, G c=05.00, K=00.60, J_{a}=01.00$.

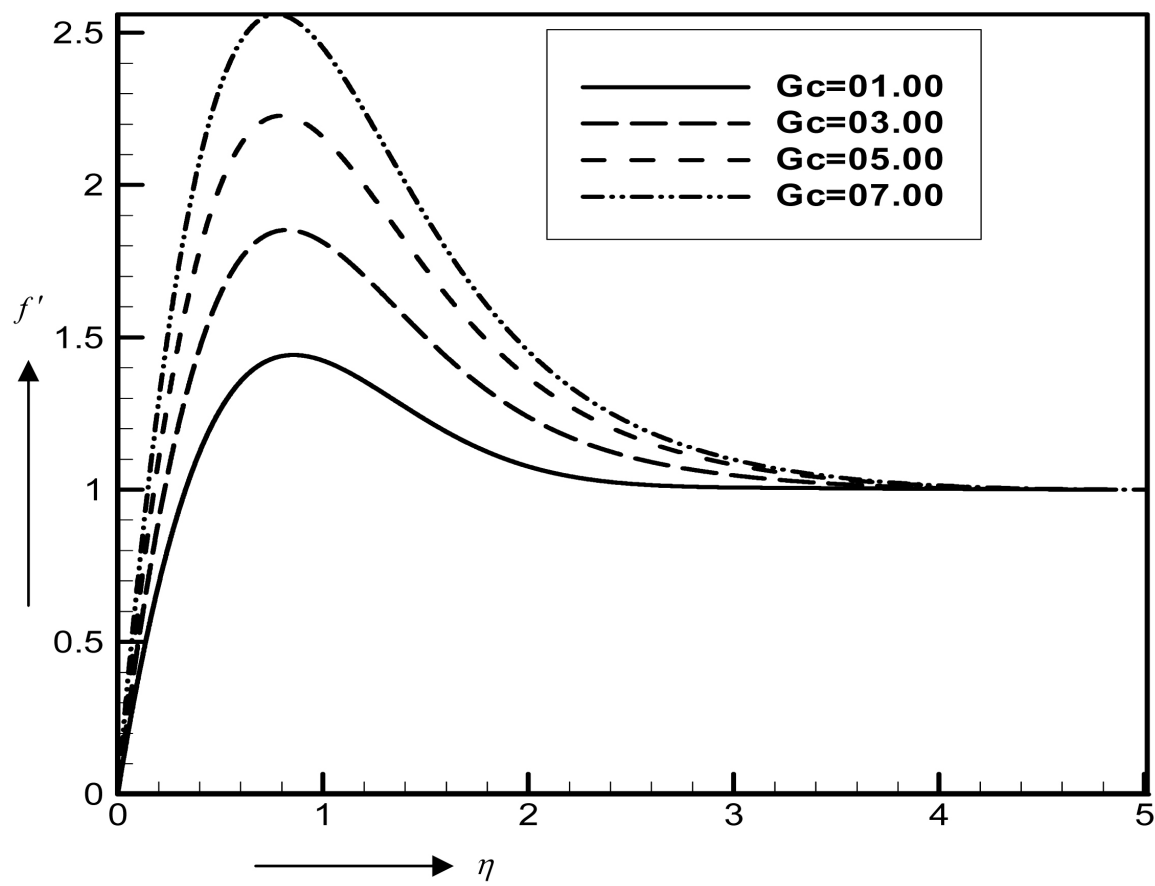

Figure 4. Velocity profile for various values of $G c$. when, $A_{1}=0.50, A_{2}=0.50, \operatorname{Pr}=00.71, S c=$ $00.22, G r=05.00, K=0.60, J_{a}=01.00$. 


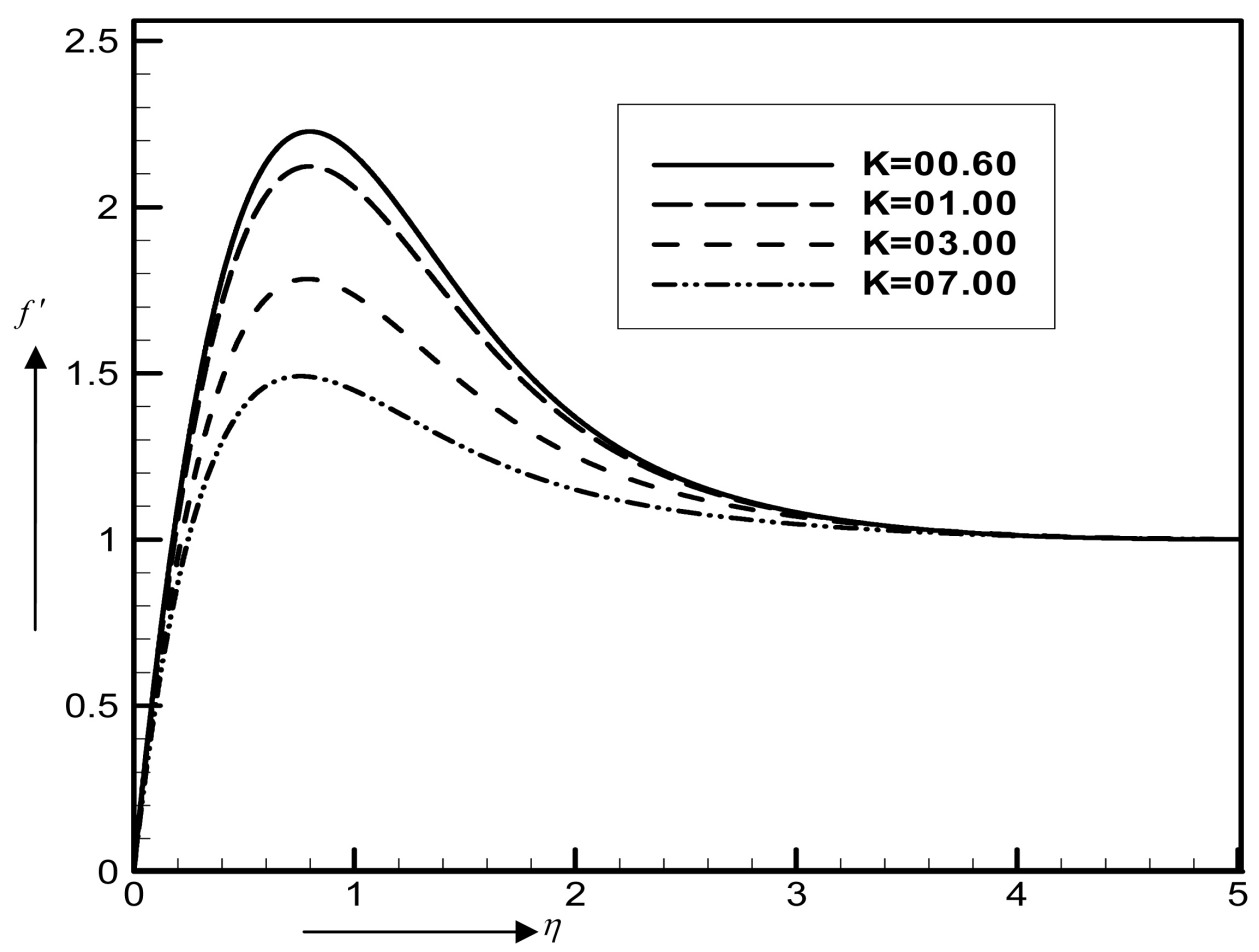

Figure 5. Velocity profile for various values of $K$. when, $A_{1}=0.50, \operatorname{Pr}=00.71, S c=0.22, G r=$ 05.00, $G c=05.00, K=0.60 . J_{a}=01.00$.

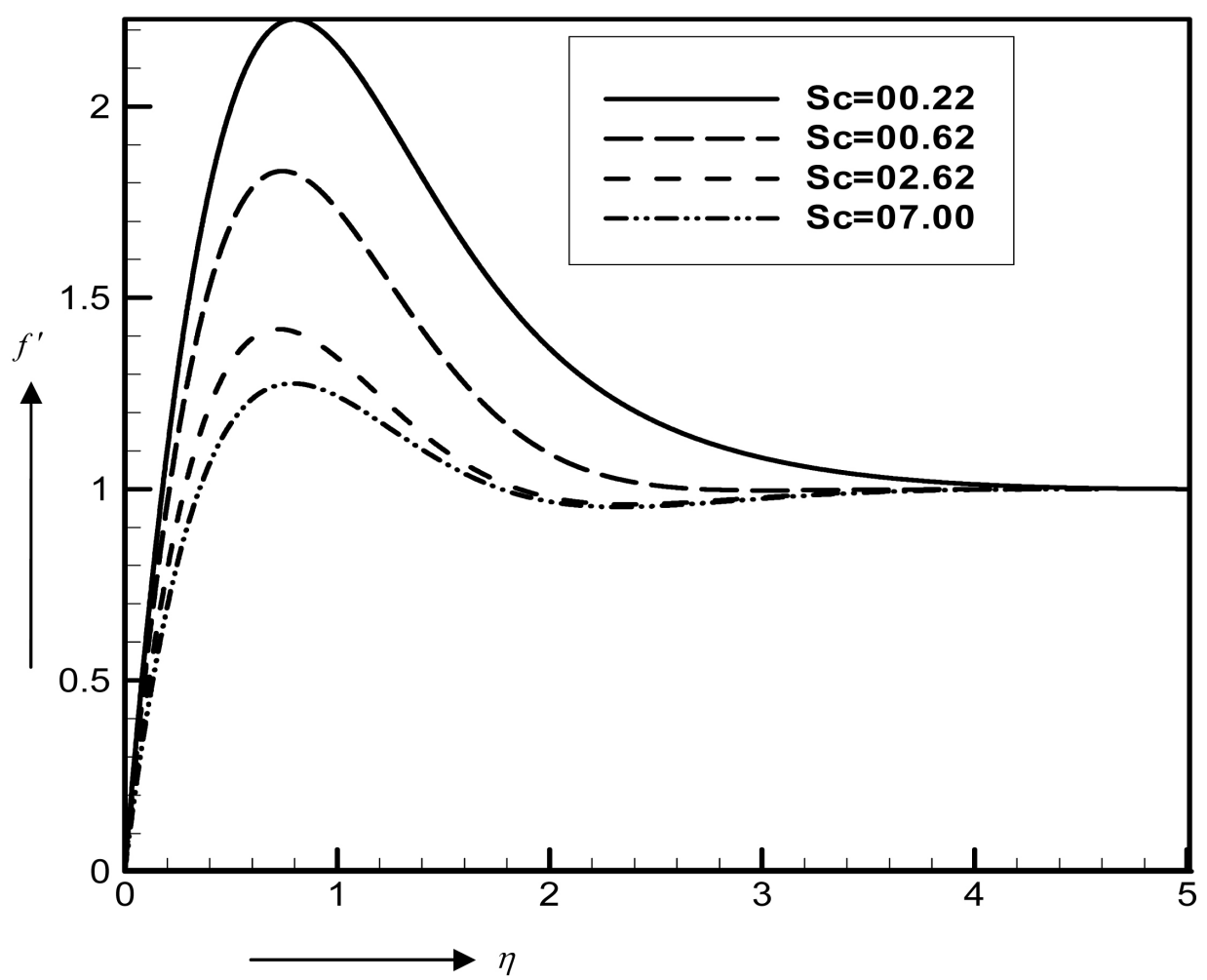

Figure 6. Velocity profile for various values of $S c$. when, $A_{1}=00.50, A_{2}=00.50, \operatorname{Pr}=00.71, G r=$ 05.00, $G c=05.00, K=00.60, J_{a}=01.00$. 


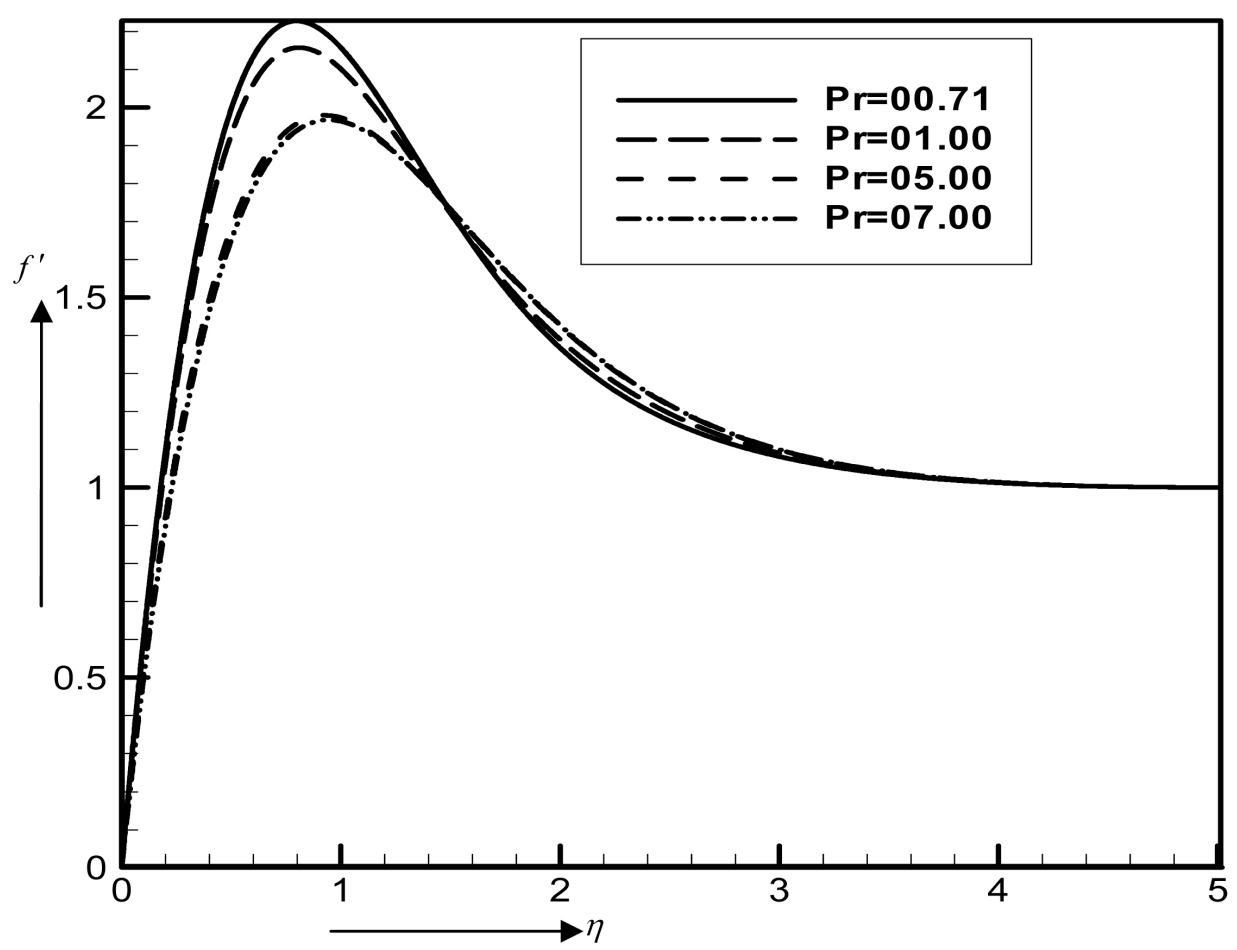

Figure 7. Velocity profile for various values of Pr. when, $A_{1}=00.50, A_{2}=00.50, S c=00.22, G r=$ $05.00, G c=05.00, K=00.60, J_{a}=01.00$.

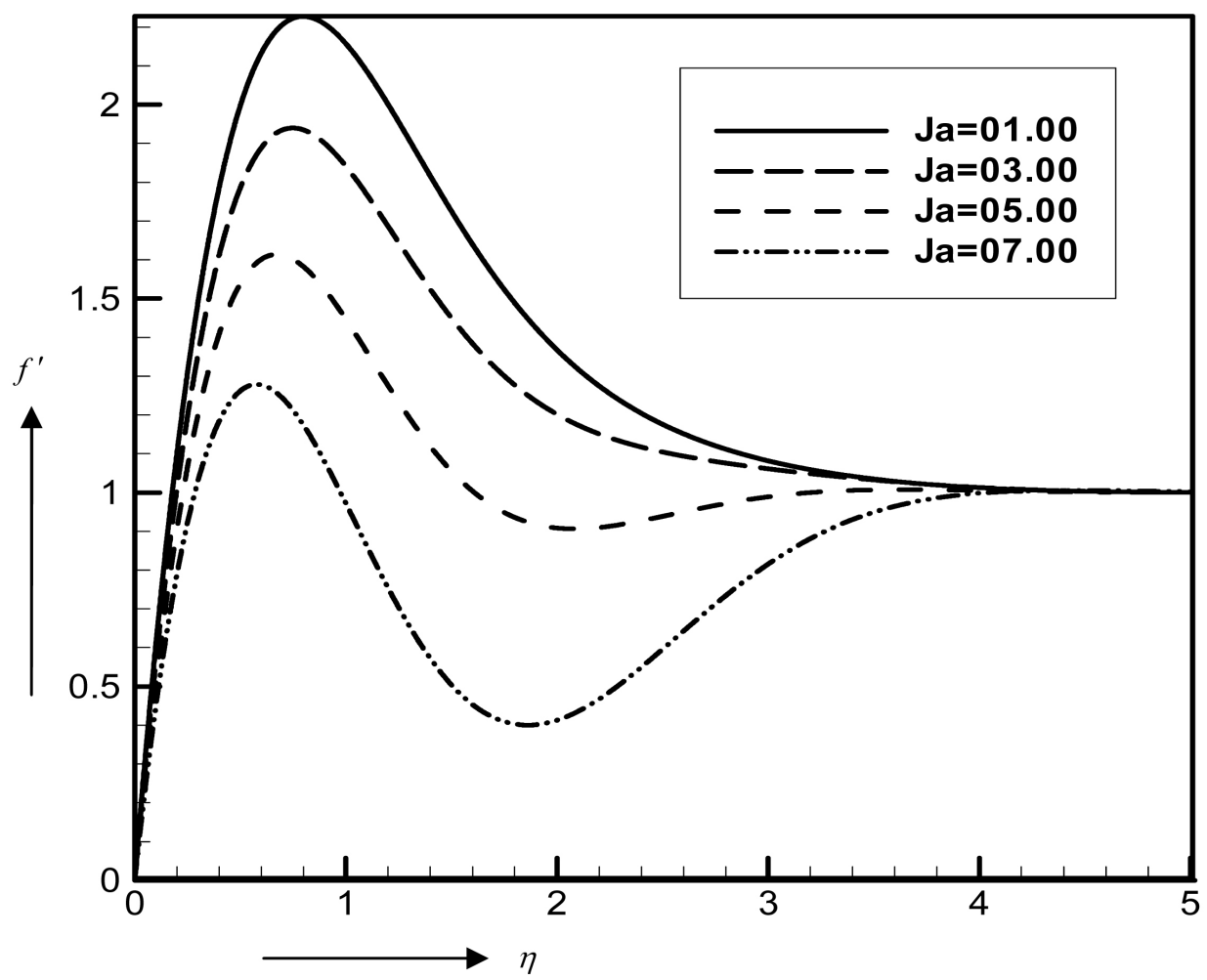

Figure 8. Velocity profile for various values of $J_{a}$. When, $A_{1}=00.50, A_{2}=00.50, \operatorname{Pr}=00.71, S c=$ $00.22, G r=05.00, G c=05.00, K=00.60$. 
mixed convective flow, the effect of Schmidt number on the velocity profile is represented in the Figure 6. It is found that the fluid velocity decreases significantly with the increases of Schmidt number.

Figure 7 reveals that the velocity profile decreases with the increase of Pr. Due to the increases of $P r$, the dynamic viscosity of the fluid increases thus the velocity of the fluid decrease gradually. We also observed in Figure 8 that velocity profile decreases rapidly and there are very tiny fluctuations with the increase of Modified Richardson number or buoyancy parameter, $J_{a}$.

\subsection{Temperature Profiles}

The behaviors of the dimensionless temperature profiles for several thermo physical parameters are illustrated in Figures 9-16. From these Figures it is observed that boundary conditions of the flow profile under consideration, the fluid temperature arrive at 1.0 then decreases exponentially to the leading edge and leads to zero far away from the plate with the with the increases of $\eta$. Figure 9 and Figure 10 represent the effects of unsteadiness parameters $A_{1}$ and $A_{2}$ on the dimensionless temperature. It is observed that in both cases the temperature profile decreases with the increases of $A_{1}$ and $A_{2}$. Figure 11 and Figure 12 represent the variation of the temperature profiles with $G r$ and $G c$. It is seen that in both cases the temperature boundary layer thickness decrease with an increase in $G r$ and $G c$.

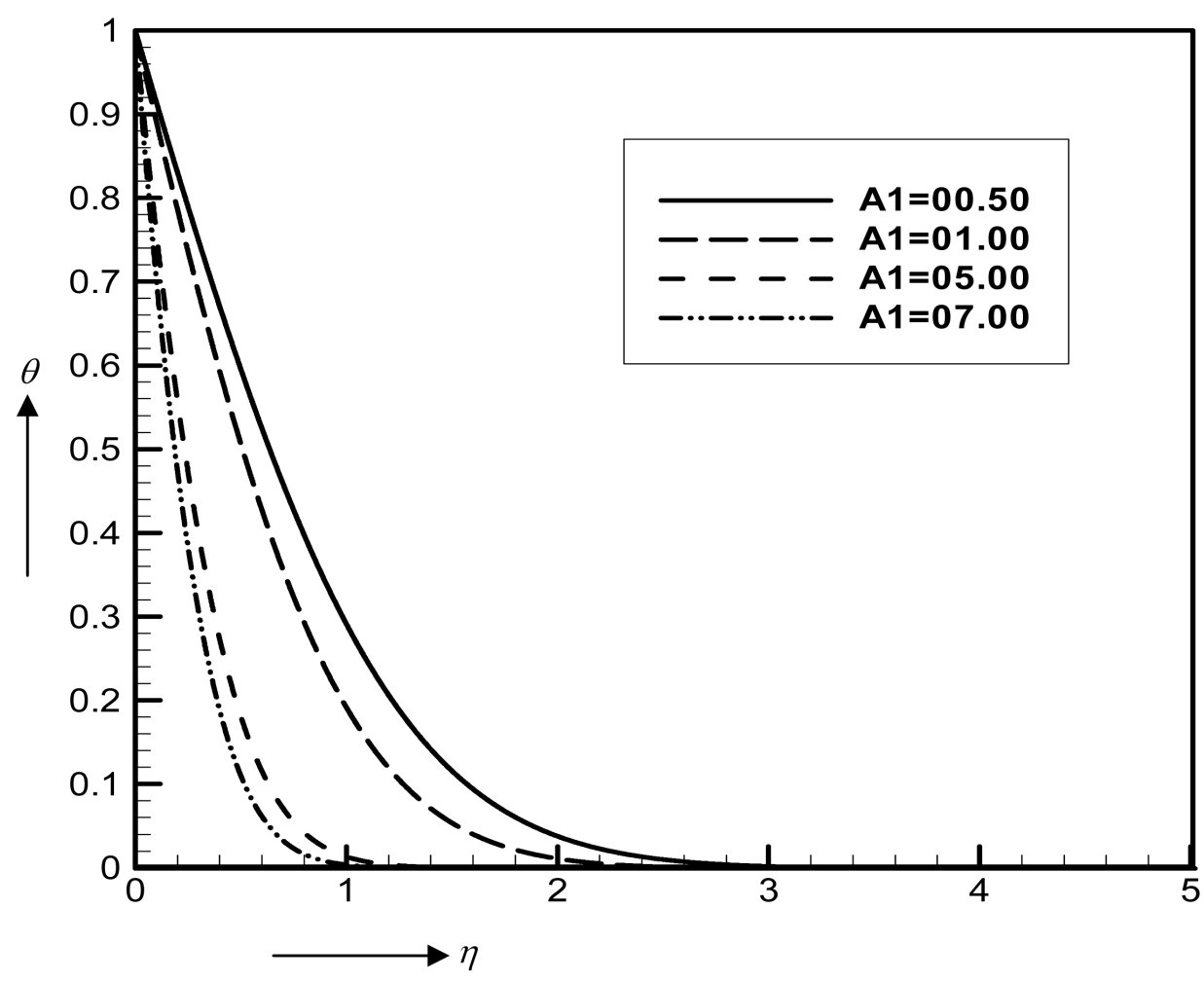

Figure 9. Temperature profile for various values of $A_{1}$. when, $A_{2}=0.50, \operatorname{Pr}=00.71, S c=00.22, G r=$ 05.00, $G c=05.00, K=00.60, J_{a}=01.00$. 


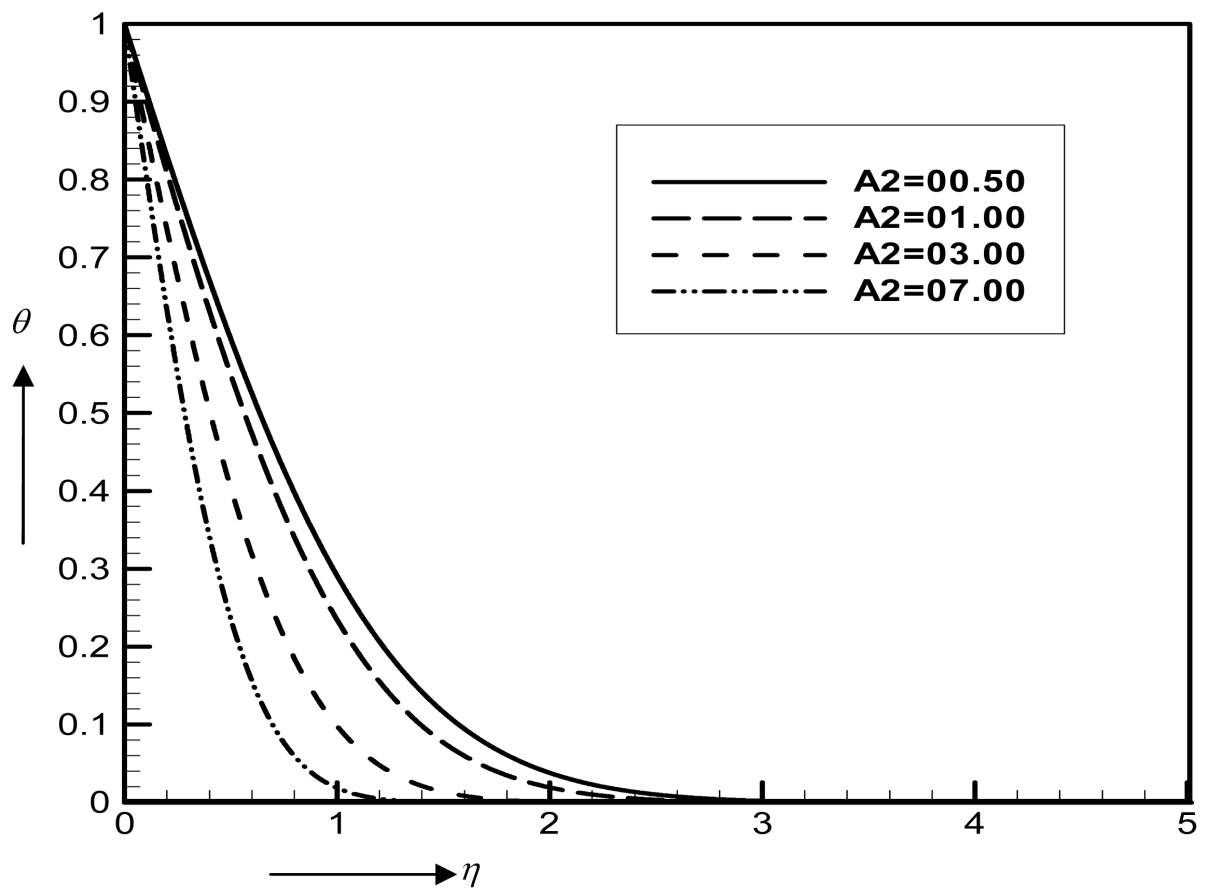

Figure 10. Temperature profile for various values of $A_{2}$. when, $A_{1}=0.50, \operatorname{Pr}=00.71, S c=$ 00.22, $G r=05.00, G c=05.00, K=0.60, J_{a}=01.00$.

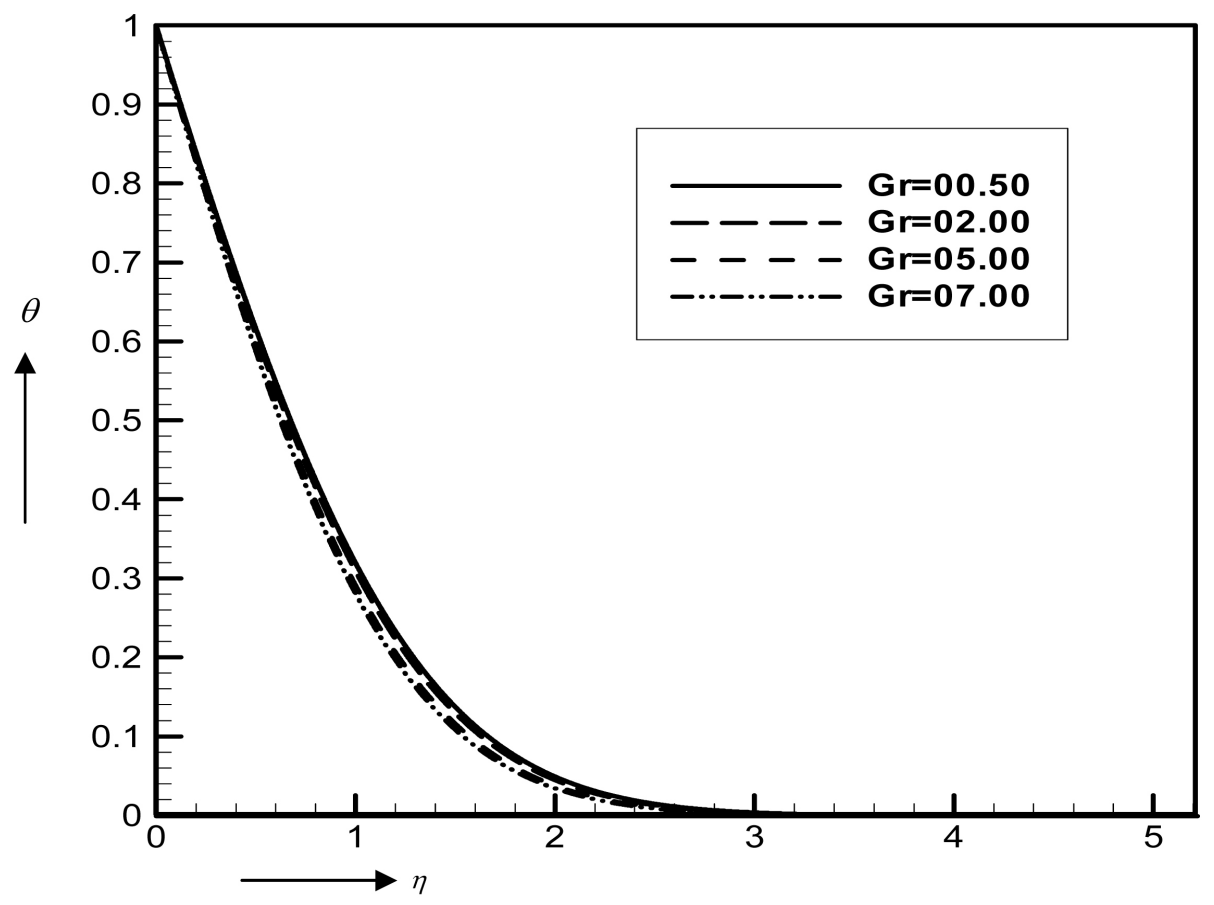

Figure 11. Temperature profile for various values of $G r$. when, $A_{1}=0.50, A_{2}=00.50, S c=$ $00.22, G c=05.00, G c=05.00, K=0.60, J_{a}=01.00$.

Figure 13 demonstrates the temperature profile for the selected values of permeability parameter $K$. It is noticed that temperature profile slightly increases for increasing 


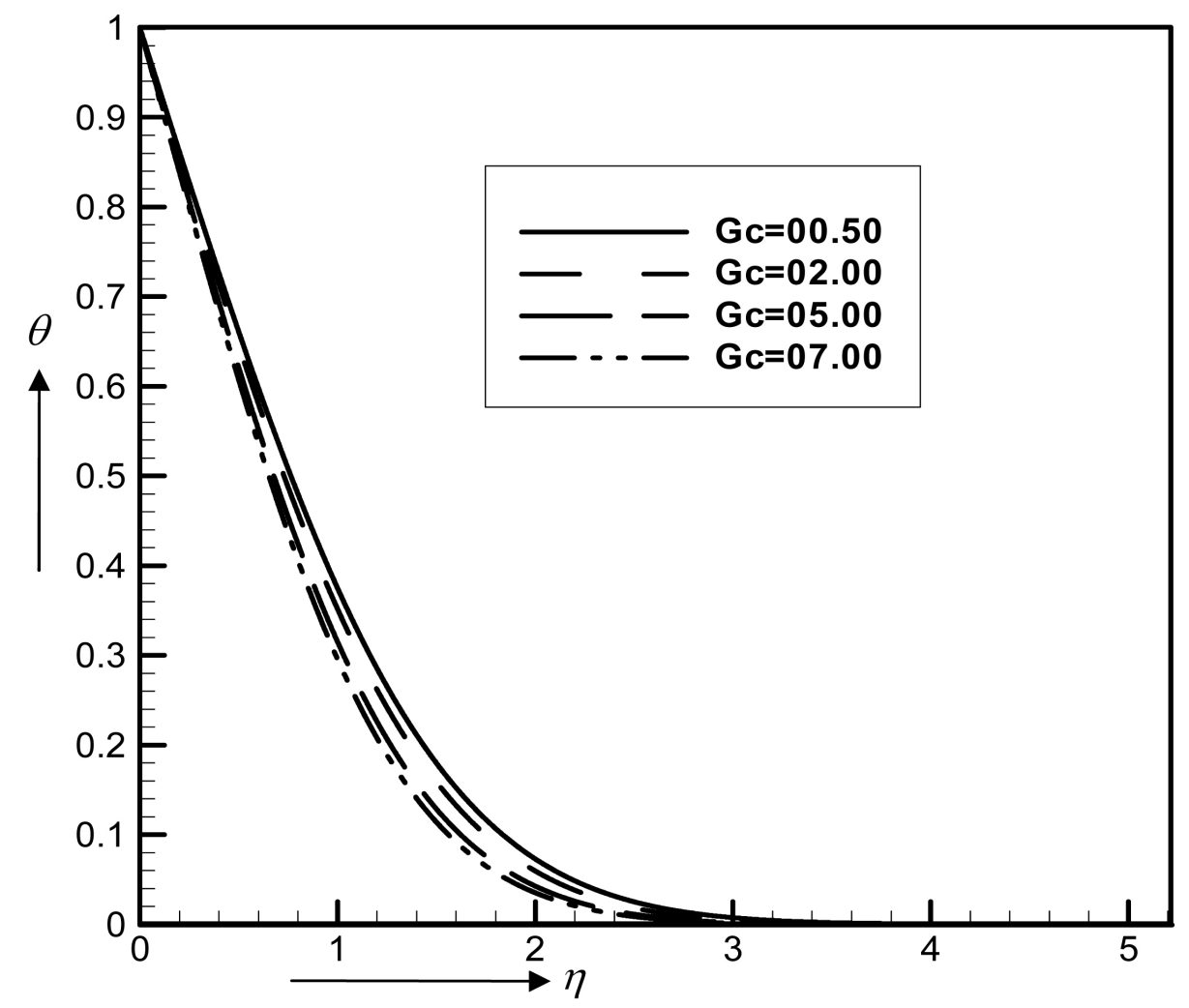

Figure 12. Temperature profile for various values of $G c$. when, $A_{1}=0.50, A_{2}=00.50, S c=$ $00.22, G r=05, \operatorname{Pr}=00.71, K=00.60, J_{a}=01.00$.

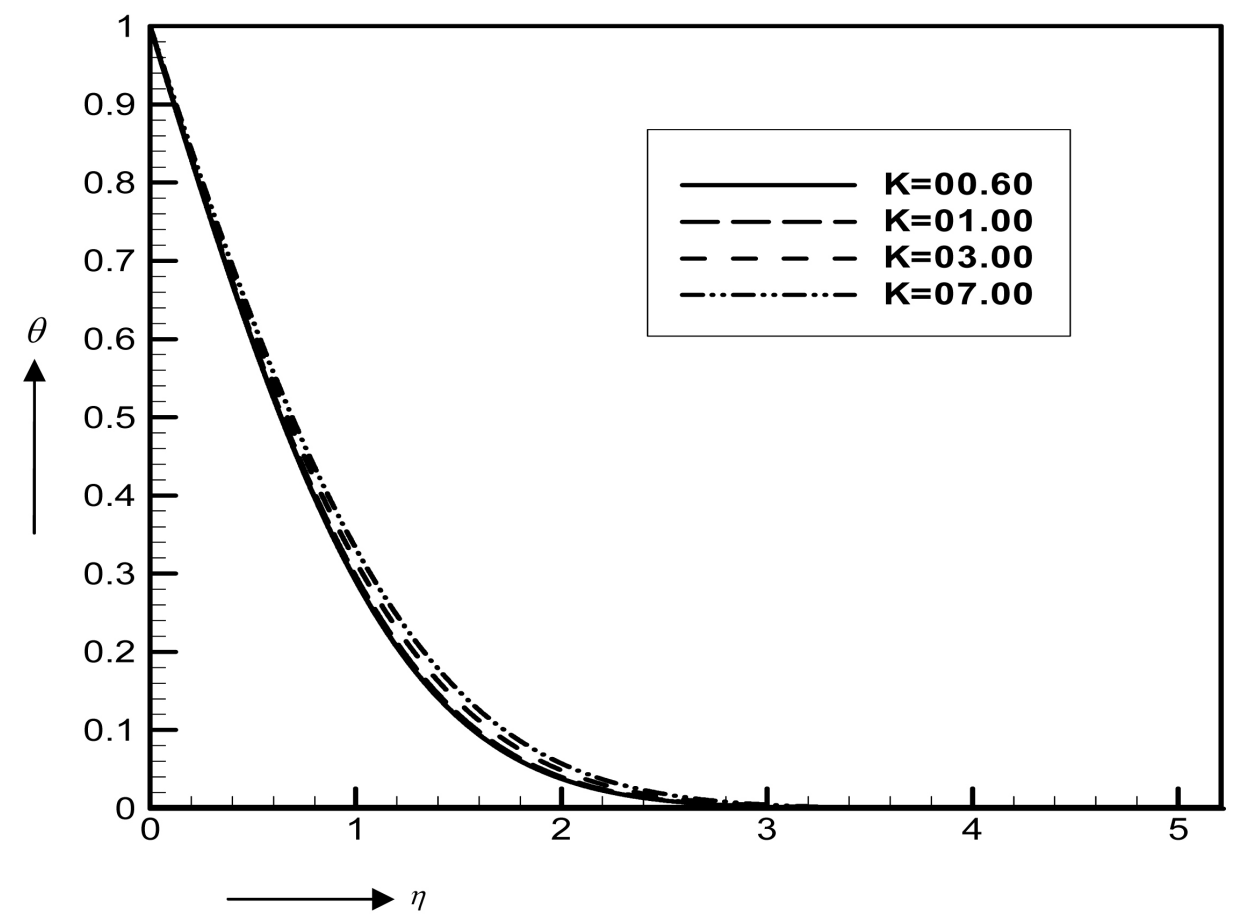

Figure 13. Temperature profile for various values of $K$. when, $A_{1}=0.50, A_{2}=0.50, S c=00.22$, $\operatorname{Pr}=00.71, G r=05.00, G c=05.00, J_{a}=01.00$. 


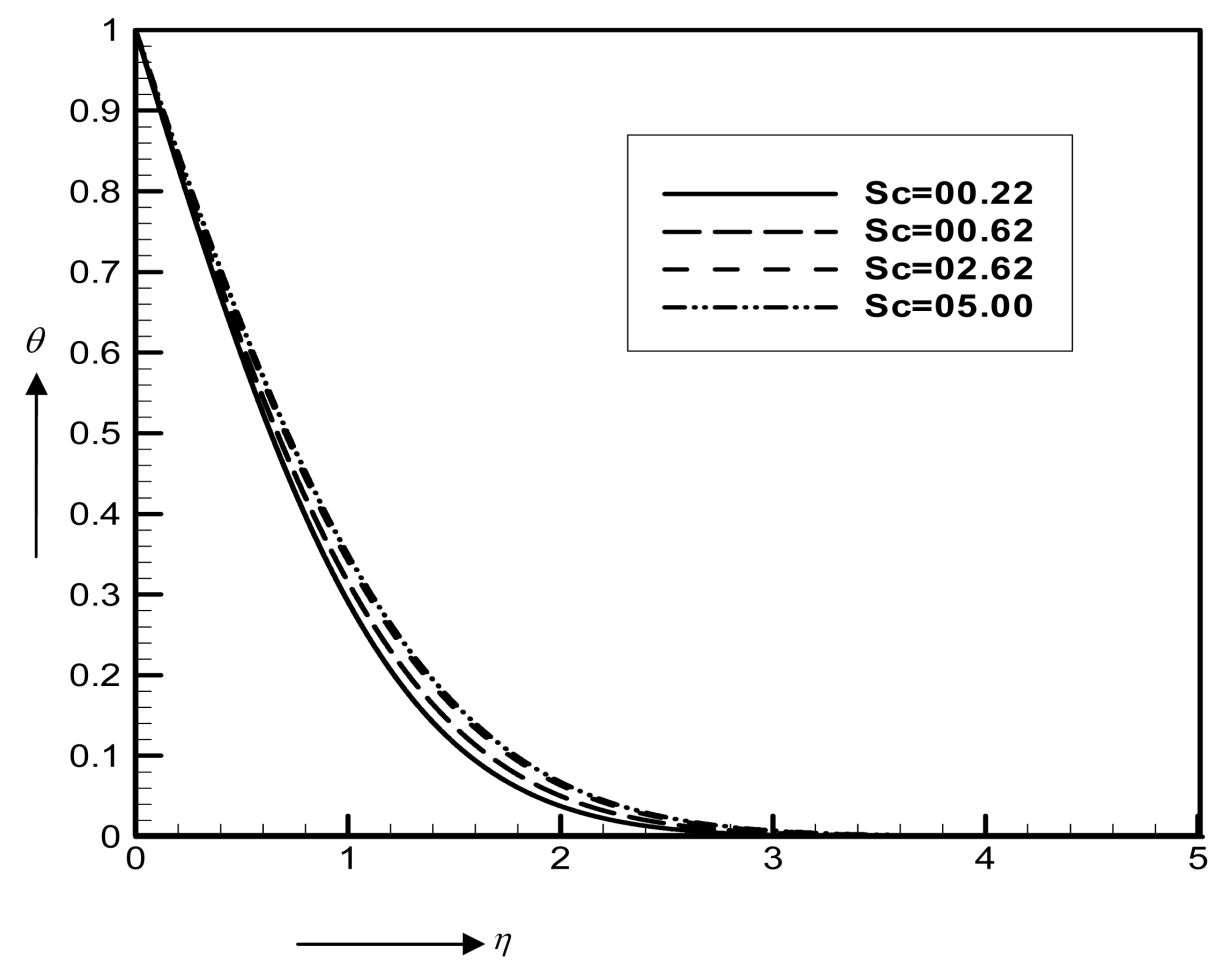

Figure 14. Temperature profile for various values of $S c$. when, $A_{1}=0.50, A_{2}=0.50, \operatorname{Pr}=00.71$, $G c=05.00, G r=05.00, K=0.60, J_{a}=01.00$.

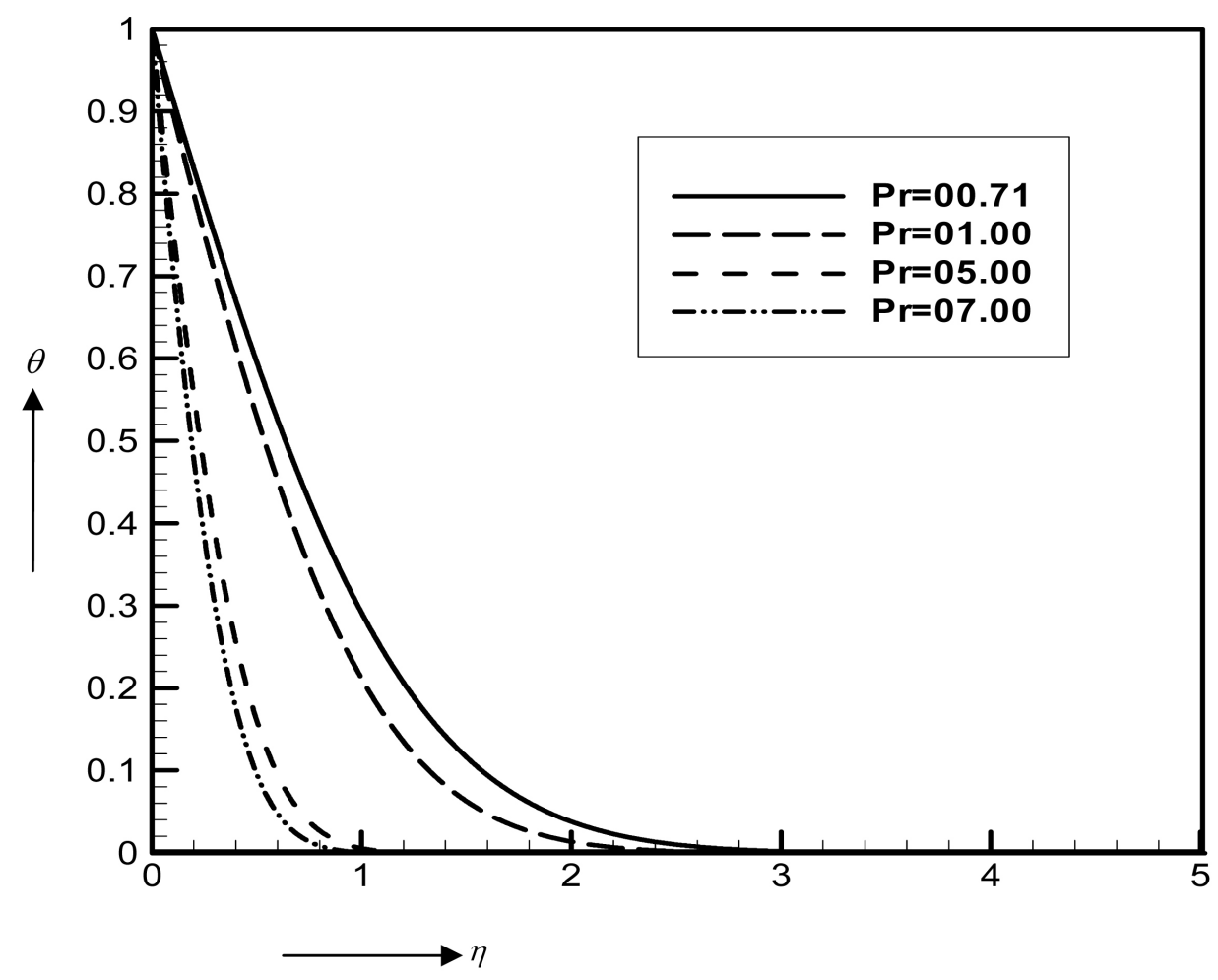

Figure 15. Temperature profile for various values of $\operatorname{Pr}$, when, $A_{1}=0.50, A_{2}=0.50, S c=00.22$, $G r=05.00, G c=05.00, K=0.60, J_{a}=01.00$. 


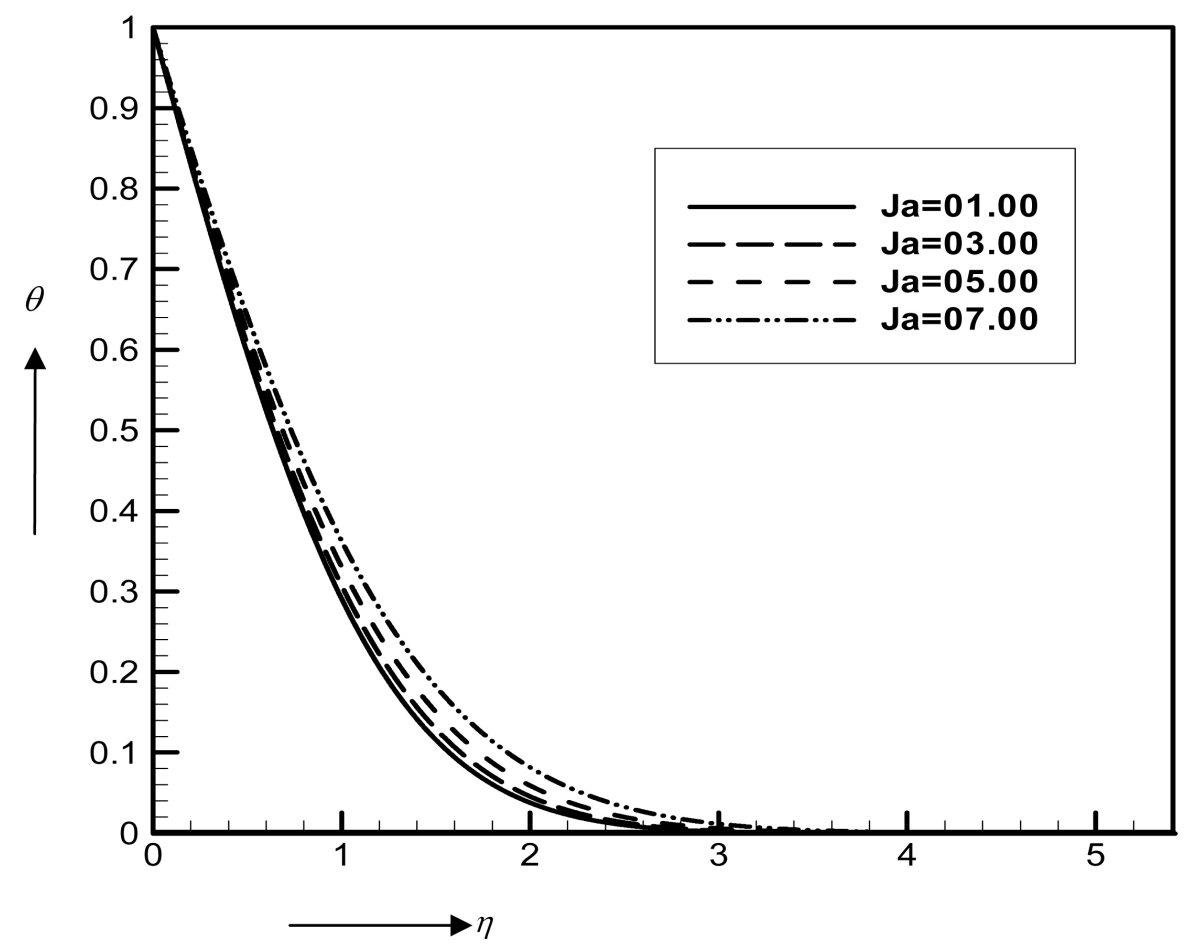

Figure 16. Temperature profile for various values of $J_{a}$, when, $A_{1}=0.50, A_{2}=0.50, \operatorname{Pr}=$ $00.71, S c=00.22, G r=05.00, G c=05.00, K=0.60$.

values of $K$.

The effect of various values of the Schmidt number, $S c$ on the dimensionless temperature profile is displayed in Figure 14. We have observed that the fluid temperature profile increases monotonically with the increases of Schmidt number.

Figure 15 exhibits the influence of the Prandtl number, Pr on the non dimensional temperature profiles in the boundary layer. We observed that the temperature profile decreases smoothly with the increase of Pr. We also observed from Figure 16 that velocity profile increases gradually with the increases of Modified Richardson number or buoyancy parameter, $J_{a}$.

\subsection{Concentration Profiles}

Figures 17-24 depict the variation on the chemical species concentration profiles for different governing parameters. From these Figures it is noted that the chemical species concentration is highest at the plate surface and decreases exponentially to zero far away from the plate satisfying the boundary conditions of the flow profile under consideration. Figure 17 and Figure 18 represent the effects of unsteadiness parameters $A_{1}$ and $A_{2}$ on the dimensionless concentration. It is observed that in both cases the concentration profile decreases with the increases of $A_{1}$ and $A_{2}$. The influence $G r$ and $G c$ on the concentration profile is illustrated in Figure 19 and Figure 20. It is noticed that in both cases concentration profile decreases slightly with the increases in $G r$ and $G c$. Figure 21 displays the concentration profile for permeability parameter $K$. It is noticed 


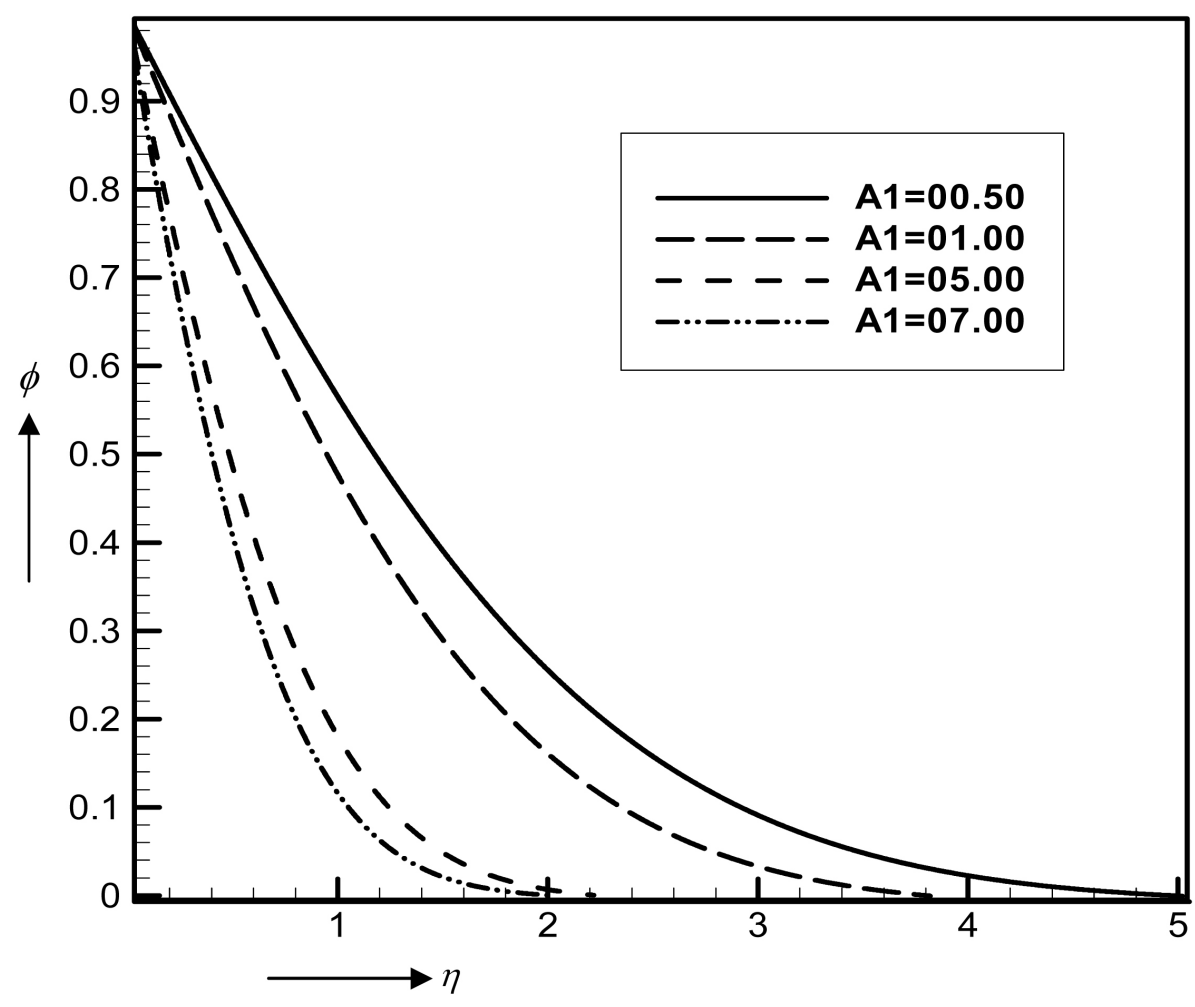

Figure 17. Concentration profile for various values of $A_{1}$, when, $A_{2}=0.50, \operatorname{Pr}=00.71, S c=$ $0.22, G r=05.00, G c=05.00, K=0.60, J_{a}=01.00$.

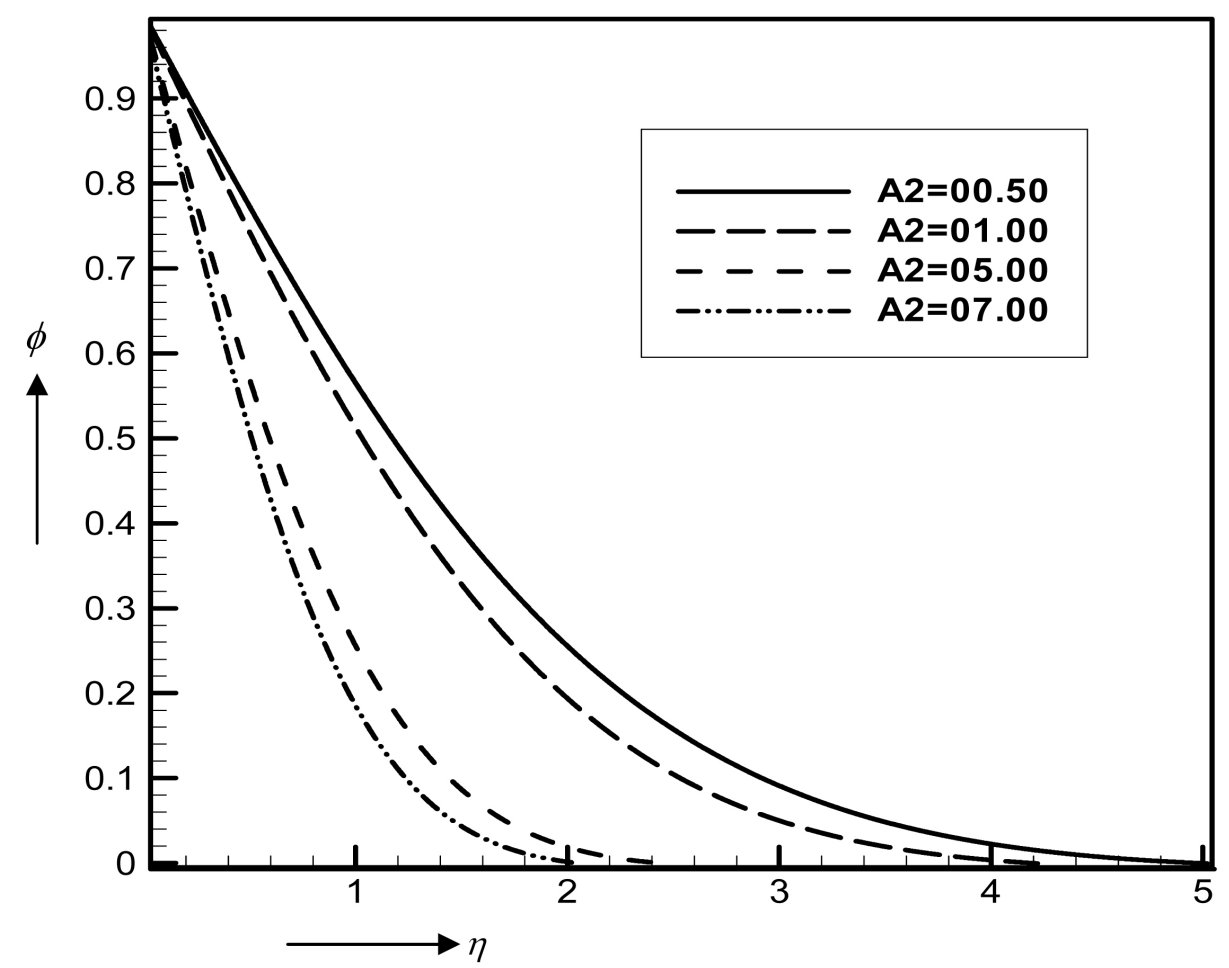

Figure 18. Concentration profile for various values of $A_{2}$, when, $A_{1}=0.50, \operatorname{Pr}=0.71, S c=$ $00.22, G r=05.00, G c=05.00, K=0.60, J_{a}=01.00$. 


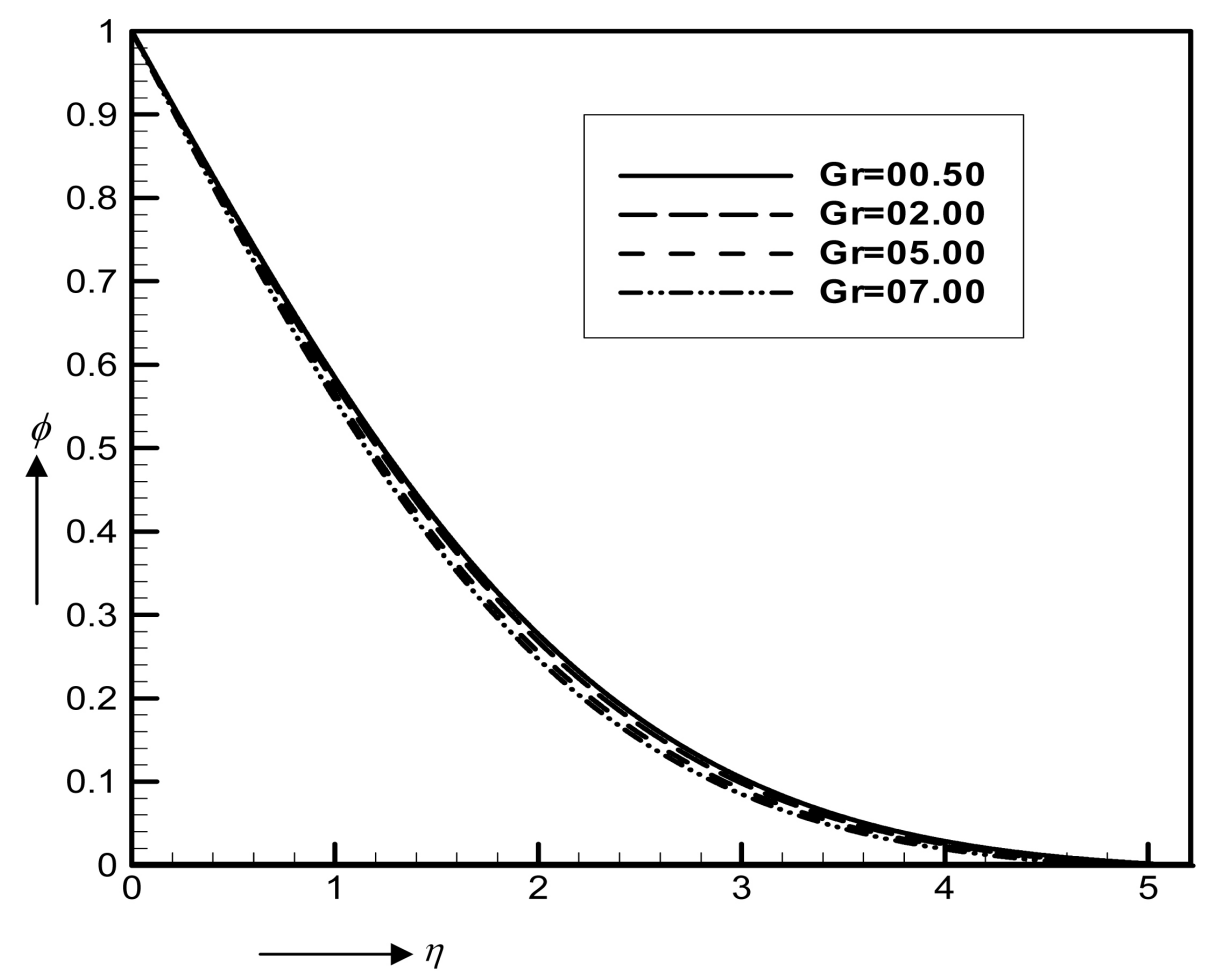

Figure 19. Concentration profile for various values of $G r$, when, $A_{1}=0.50, A_{2}=00.50, \operatorname{Pr}=$ $00.71, S c=00.22, G c=05.00, K=0.60, J_{a}=01.00$.

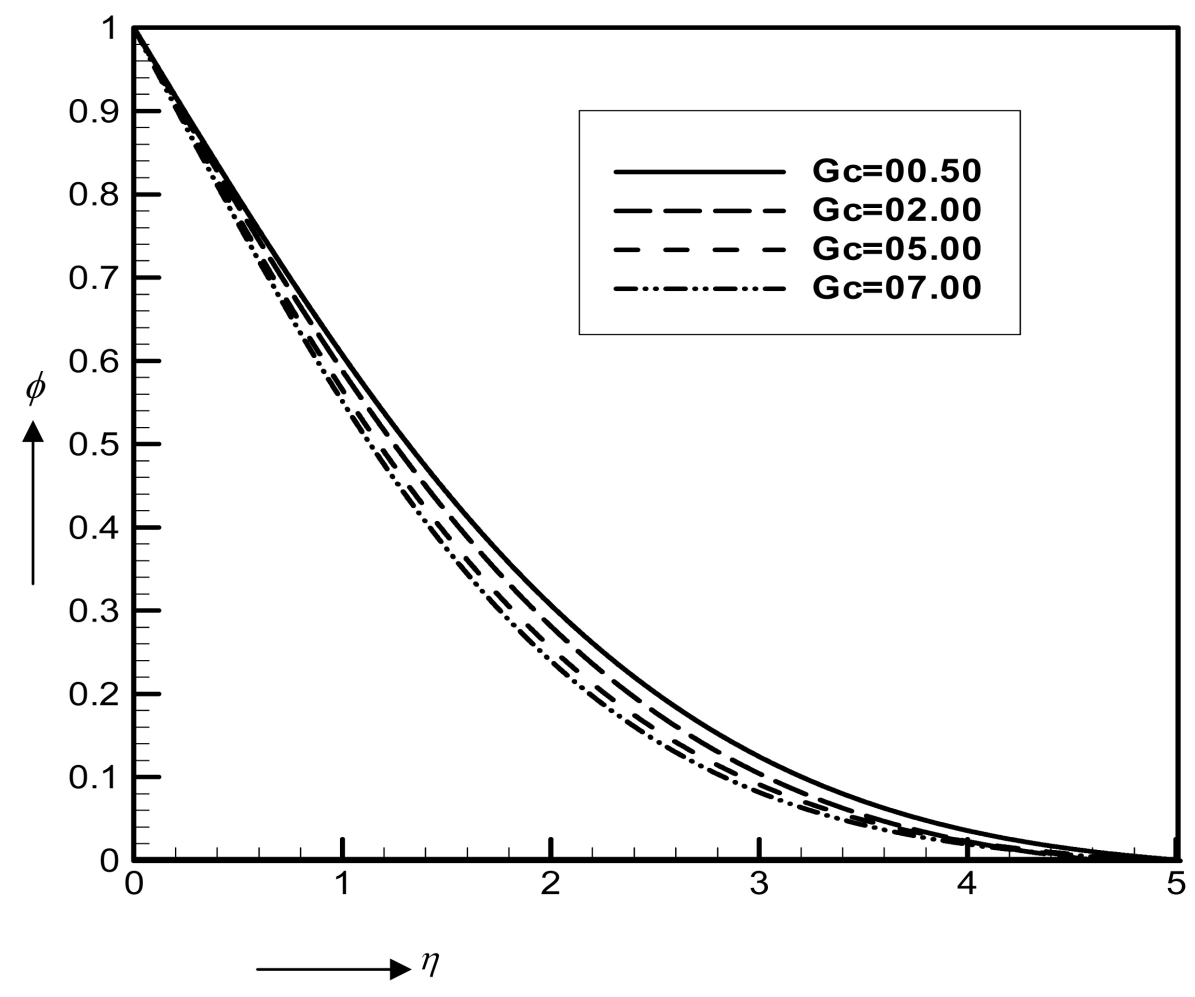

Figure 20. Concentration profile for various values of $G c$, when, $A_{1}=0.50, A_{2}=00.50, \operatorname{Pr}=$ $00.71, S c=00.22, G r=05.00, K=0.60, J_{a}=01.00$. 


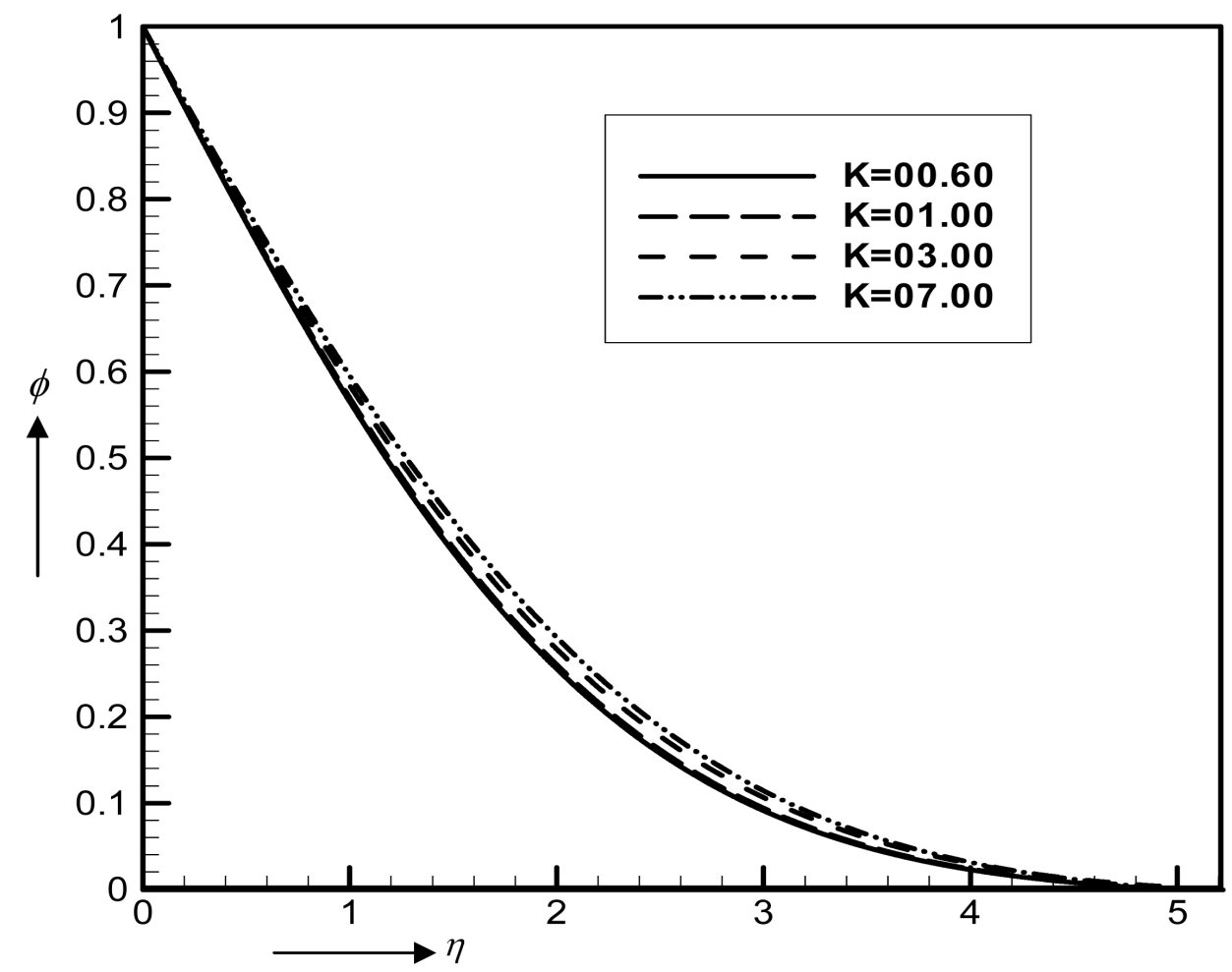

Figure 21. Concentration profile for various values of $K$, when, $A_{1}=0.50, A_{2}=0.50, \operatorname{Pr}=00.71, S c$ $=00.22, G r=05.00, G c=05.00, J_{a}=01.00$.

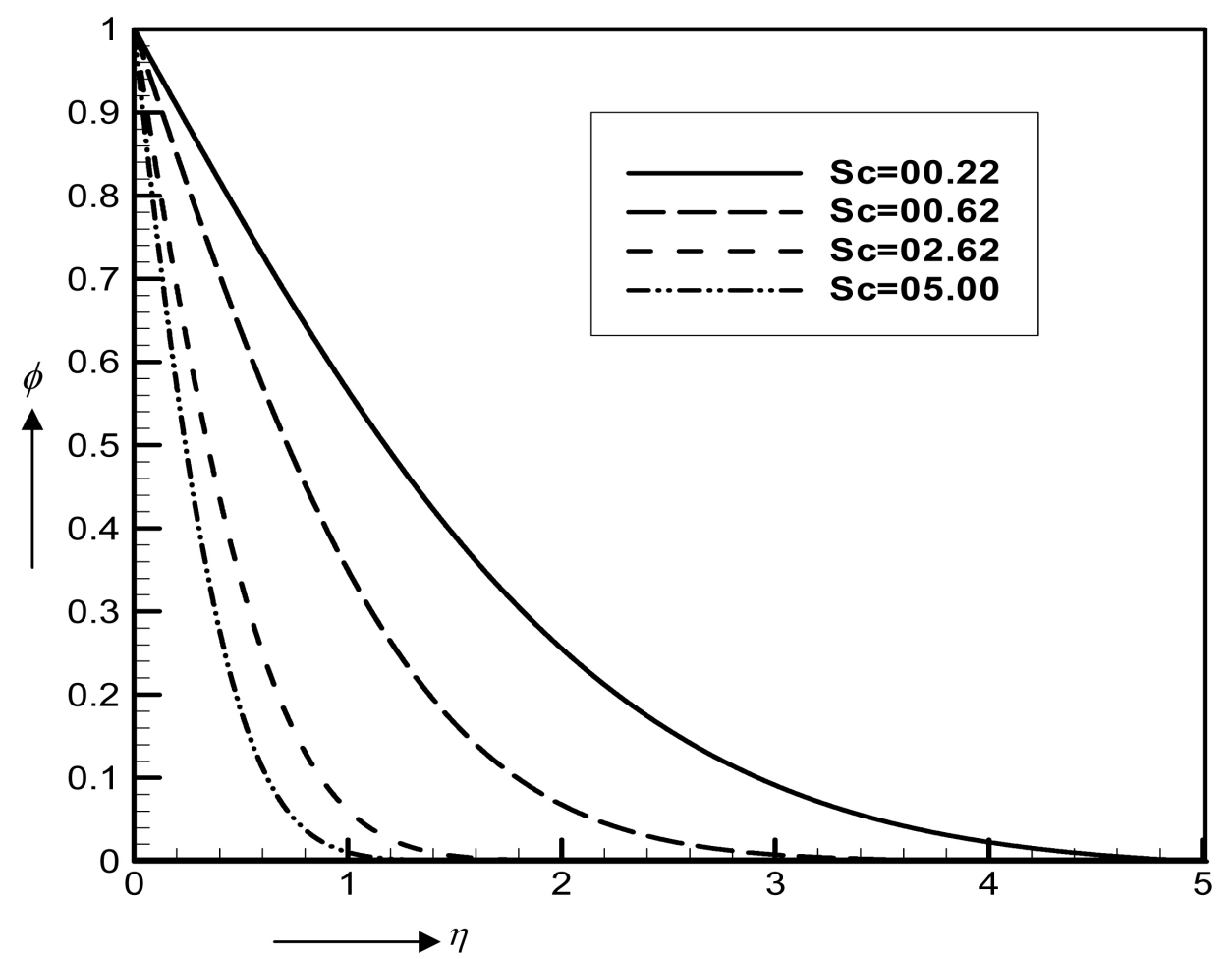

Figure 22. Concentration profile for various values of $S c$, when, $A_{1}=0.50, A_{2}=00.50, \operatorname{Pr}=00.71$, $G r=05.00, G c=05.00, K=0.60, J_{a}=01.00$. 


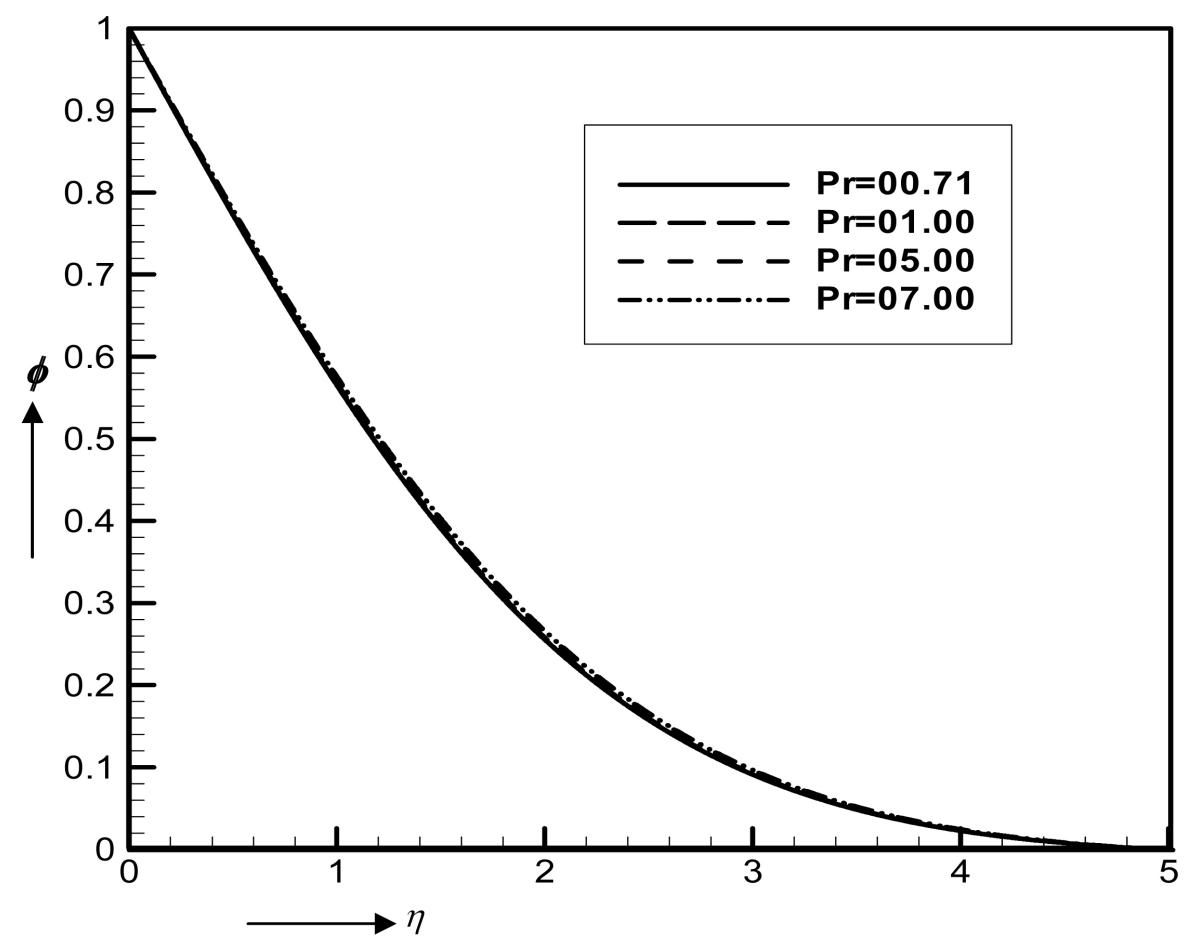

Figure 23. Concentration profile for various values of $P r$, when, $A_{1}=0.50, A_{2}=0.50, S c=$ $00.22, G r=05.00, G c=05.00, K=00.60, J_{a}=01.00$.

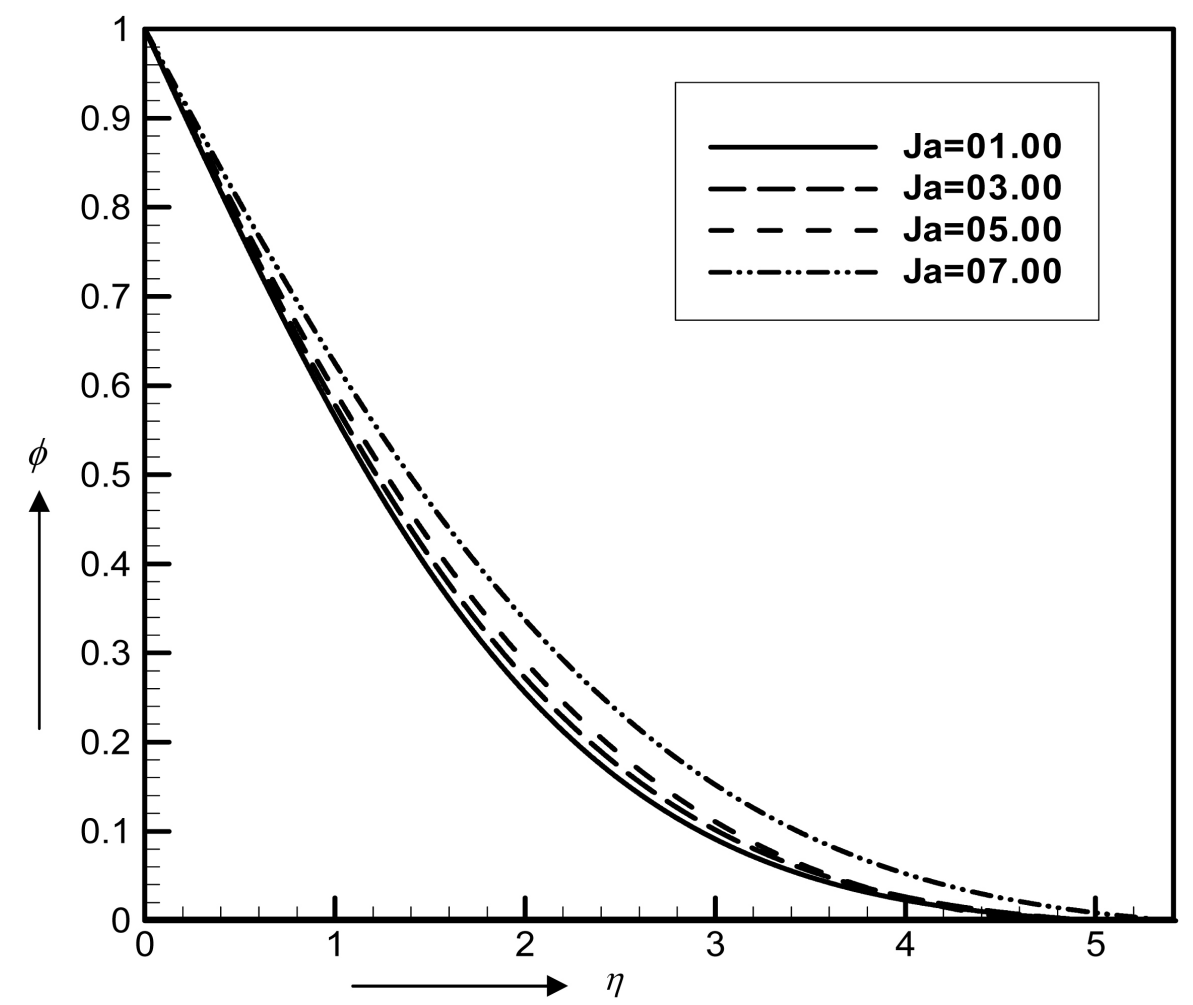

Figure 24. Concentration profile for various values of $J_{a}$, when, $A_{1}=0.50, A_{2}=0.50, \operatorname{Pr}=$ 00.71, $S c=00.22, G r=05.00, G c=05.00, K=00.60$. 
that concentration increases monotonically for the increasing values of $K$.

The effects of the Schmidt number, $S c$ on the dimensionless concentration profile is represented in Figure 22. In this Figure we observe that the concentration decreases rapidly with the increase of Schmidt number. The Schmidt number embodies the ratio of the momentum diffusivity to the mass (Species) diffusivity and relates the relative thickness of the hydrodynamics boundary layer and mass transfer (concentration) boundary layer. Figure 23 illustrates the effect of the Prandtl number, $\operatorname{Pr}$ on the non dimensional concentration profiles in the boundary layer. Concentration profiles exhibits no significant effect due to the increases of Pr. Variation of concentration profile due the Richardson number or buoyancy parameter $\left(J_{a}\right)$ is represented in Figure 24. It is seen that Concentration profile increases for the increasing values of $J_{a}$.

Tables 1-8 illustrate numerical results to exhibit the effect of several parameters on the skin-friction co-efficient, Nusselt number and Sherwood number for the physical interest of the problem. Table 1 and Table 2 depict that, both Nusselt number and Sherwood number increase with the increase of the unsteadiness parameters $A_{1} \& A_{2}$

Table 1. $f^{\prime \prime}(0), \theta^{\prime}(0)$ and $\phi^{\prime}(0)$ for different values of $A_{1}$.

\begin{tabular}{cccc}
\hline$A_{1}$ & $f^{\prime \prime}(0)$ & $-\theta^{\prime}(0)$ & $-\phi^{\prime}(0)$ \\
\hline 00.50 & 6.6684047 & 0.86623414 & 0.4638774 \\
00.60 & 6.7096433 & 0.88887867 & 0.4703514 \\
00.70 & 6.7503441 & 0.91178743 & 0.4768741 \\
00.80 & 6.7835569 & 0.93478588 & 0.4843823 \\
\hline
\end{tabular}

Table 2. $f^{\prime \prime}(0), \theta^{\prime}(0)$ and $\phi^{\prime}(0)$ for different values of $A_{2}$.

\begin{tabular}{cccc}
\hline$A_{2}$ & $f^{\prime \prime}(0)$ & $-\theta^{\prime}(0)$ & $-\phi^{\prime}(0)$ \\
\hline 00.50 & 6.6684047 & 0.86623414 & 0.4638774 \\
00.60 & 6.5837669 & 0.88911971 & 0.4770399 \\
00.70 & 6.5026486 & 0.91176817 & 0.4901558 \\
00.80 & 6.4247905 & 0.93417005 & 0.5032540 \\
\hline
\end{tabular}

Table 3. $f^{\prime \prime}(0), \theta^{\prime}(0)$ and $\phi^{\prime}(0)$ for different values of Pr.

\begin{tabular}{cccc}
\hline$P r$ & $f^{\prime \prime}(0)$ & $-\theta^{\prime}(0)$ & $-\phi^{\prime}(0)$ \\
\hline 00.71 & 6.6684047 & 0.86623414 & 0.4638774 \\
01.00 & 6.4879364 & 1.03522239 & 0.4612288 \\
05.00 & 5.7126763 & 2.56639249 & 0.4524284 \\
07.00 & 5.5704654 & 3.18305329 & 0.4512952 \\
\hline
\end{tabular}


Table 4. $f^{\prime \prime}(0), \theta^{\prime}(0)$ and $\phi^{\prime}(0)$ for different values of $S c$.

\begin{tabular}{cccc}
\hline$S c$ & $f^{\prime \prime}(0)$ & $-\theta^{\prime}(0)$ & $-\phi^{\prime}(0)$ \\
\hline 00.22 & 6.6684047 & 0.86623414 & 0.4638774 \\
00.62 & 5.9529296 & 0.82996263 & 0.7705062 \\
02.62 & 5.0214731 & 0.79034800 & 1.6753632 \\
05.00 & 4.6631048 & 0.77886475 & 2.4818305 \\
\hline
\end{tabular}

Table 5. $f^{\prime \prime}(0), \theta^{\prime}(0)$ and $\phi^{\prime}(0)$ for different values of $G r$.

\begin{tabular}{cccc}
\hline$G r$ & $f^{\prime \prime}(0)$ & $-\theta^{\prime}(0)$ & $-\phi^{\prime}(0)$ \\
\hline 00.50 & 4.6450273 & 0.81946908 & 0.4414440 \\
02.00 & 5.3353043 & 0.83613835 & 0.4500845 \\
05.00 & 6.6684047 & 0.86623414 & 0.4638774 \\
07.00 & 7.5143810 & 0.88388685 & 0.4730272 \\
\hline
\end{tabular}

Table 6. $f^{\prime \prime}(0), \theta^{\prime}(0)$ and $\phi^{\prime}(0)$ for different values of $G c$.

\begin{tabular}{cccc}
\hline$G c$ & $f^{\prime \prime}(0)$ & $-\theta^{\prime}(0)$ & $-\phi^{\prime}(0)$ \\
\hline 00.50 & 3.8369068 & 0.77442428 & 0.4158638 \\
02.00 & 4.8149205 & 0.80935822 & 0.4370507 \\
05.00 & 6.6684047 & 0.86623414 & 0.4638774 \\
07.00 & 7.8290644 & 0.89716045 & 0.4804288 \\
\hline
\end{tabular}

Table 7. $f^{\prime \prime}(0), \theta^{\prime}(0)$ and $\phi^{\prime}(0)$ for different values of $K$.

\begin{tabular}{cccc}
\hline$K$ & $f^{\prime \prime}(0)$ & $-\theta^{\prime}(0)$ & $-\phi^{\prime}(0)$ \\
\hline 00.60 & 6.6684047 & 0.86623414 & 0.4638774 \\
01.00 & 6.4963956 & 0.85764149 & 0.4591429 \\
03.00 & 6.0404735 & 0.82913084 & 0.4424230 \\
07.00 & 5.9078417 & 0.80429643 & 0.4297748 \\
\hline
\end{tabular}

while Skin-friction co-efficient increases for the increasing of $A_{1}$ and decreases for the increasing of $A_{2}$. It is shown in Table 3 that, with the increases of the Prandtl number $(P r)$, both skin-friction co-efficient and Nusselt number decrease while Sherwood number increases. Again in Table 4, it is observed that with the increases of the Schmidt number $(S c)$, Skin friction coefficient and Sherwood number decrease whereas Nusselt number increases. Moreover, Table 5 \& Table 6 reveal that skin-friction coefficient, Nusselt number and Sherwood number increase with the increase of buoyancy forces $(G r, G c)$. Table $7 \&$ Table 8 also illustrate that Skin friction coefficient, Nusselt 
Table 8. $f^{\prime \prime}(0), \theta^{\prime}(0)$ and $\phi^{\prime}(0)$ for different values of $J_{a}$.

\begin{tabular}{cccc}
\hline$J_{a}$ & $f^{\prime \prime}(0)$ & $-\theta^{\prime}(0)$ & $-\phi^{\prime}(0)$ \\
\hline 01.00 & 6.6684047 & 0.86623414 & 0.4638774 \\
03.00 & 6.2020847 & 0.84179466 & 0.4489248 \\
05.00 & 5.6632770 & 0.80856924 & 0.4321363 \\
07.00 & 5.0722075 & 0.76434371 & 0.3974721 \\
\hline
\end{tabular}

number and Sherwood number decrease with the increase of the Permeability parameter $(K)$ and buoyancy parameter $\left(J_{a}\right)$.

\section{Conclusion}

Mixed convective boundary layer flow of viscous incompressible fluid has been investigated for unsteady flow along horizontal isothermal plate through similarity solutions. It is concluded that the fluid velocity, temperature and concentration profiles decrease as the unsteady parameter increases. Both fluid velocity and temperature decrease as the Prandtl number $(P r)$ increases but no significant effect on concentration. It is noted that velocity and concentration profiles exhibit significant changes while temperature exhibits minor change for the variation of Schmidt number $(S c)$. It is also revealed that velocity and concentration are higher at lower Schmidt number for low Prandtl fluid. Both the skin-friction co-efficient and Nusselt number decrease whereas Sherwood number increases with the increases of the Prandtl number $(P r)$. Skin friction coefficient and Sherwood number decrease whereas Nusselt number increases with the increases of the Schmidt number $(S c)$. Moreover, Nusselt number and Sherwood number decrease but skin-friction co-efficient increases with the increase of buoyancy forces ( $G r$ and $G c$ ). Again, Nusselt number and Sherwood number increase moreover Skin friction coefficient decreases with the increase of the Permeability parameter $(K)$ and buoyancy parameter $\left(J_{a}\right)$. It is hoped that this study will serve as a complement to the previous studies in engineering and scientific research.

\section{Acknowledgements}

The authors are highly grateful to the authority of Chittagong University of Engineering and Technology (CUET) for providing technical supports during this research work at Simulation Lab, Department of Mathematics, CUET, Chittagong, Bangladesh.

\section{References}

[1] Stewartson, K. (1964) The Theory of Laminar Boundary Layers in Compressible Fluid. Oxford Mathematical Monograph. Journal of Applied Mathematics and Mechanics, 44, 413.

[2] Crane, L.J. (1970) Flow past a Stretching Plate. Journal of Applied Mathematics and Physics, 21, 645-647 https://doi.org/10.1007/bf01587695

[3] Gupta, P.S. and Gupta, A.S. (1977) Heat and Mass Transfer on a Stretching Sheet with Suction or Blowing. The Canadian Journal of Chemical Engineering, 55, 744-746. 


\section{https://doi.org/10.1002/cjce.5450550619}

[4] Johnson, C.H. and Cheng, P. (1978) Possible Similarity Solution for Free Convection Boundary Layers Adjacent to Flat Plates in Porous Media. International Journal of Heat and Mass Transfer, 21, 709-718. https://doi.org/10.1016/0017-9310(78)90032-7

[5] Afzal, N. and Hussain, T. (1984) Mixed Convection over a Horizontal Plate. Journal of Heat Transfer, 106, 240-241. https://doi.org/10.1115/1.3246644

[6] Kumari, M., Slaouti, A., Nakamura, S., Takhar, H.S. and Nath, G. (1986) Unsteady Free Convection Flow over a Continuous Moving Vertical Surface. Acta Mechanica, 116, 75-82. https://doi.org/10.1007/BF01171421

[7] Slaouti, A., Takhar, H.S. and Nath, G. (1998) Unsteady Free Convection Flow in the Stagnation Point Region of a Three-Dimensional Body. International Journal of Heat and Mass Transfer, 41, 3397-3408. https://doi.org/10.1016/S0017-9310(98)00080-5

[8] Lagree, P.-Y. (2001) Removing the Marching Breakdown of the Boundary-Layer Equations for Mixed Convection above a Horizontal Plate. International Journal of Heat and Mass Transfer, 44, 3359-3372. https://doi.org/10.1016/S0017-9310(00)00361-6

[9] Kim, J., Kang, Y.T. and Choi, C.K. (2004) Analysis of Mixed Convective Instability and Heat Transfer Characteristics of Nanofluids. Physics of Fluids, 16, 2395-2401. https://doi.org/10.1063/1.1739247

[10] Chamkha, A.J. and Al-Mudhaf, A. (2005) Unsteady Heat and Mass Transfer from a Rotating Vertical Cone with a Magnetic Field and Heat Generation or Absorption Effects. International Journal of Thermal Science, 44, 267-276.

https://doi.org/10.1016/j.ijthermalsci.2004.06.005

[11] Aydin, O. and Kaya, A. (2005) Laminar Boundary Layer Flow over a Horizontal Permeable Flat Plate. Applied Mathematics and Computation, 161, 229-240. https://doi.org/10.1016/j.amc.2003.12.021

[12] Ali, M.E. and Magyari, E. (2007) Unsteady Fluid and Heat Flow Induced by a Submerged Stretching Surface while Its Steady Motion Is Slowed Down Gradually. International Journal of Heat and Mass Transfer, 50, 188-195. https://doi.org/10.1016/j.ijheatmasstransfer.2006.06.021

[13] Ali, M.Y. and Touhid, H.M.M. (2012) Similarity Solutions for Unsteady Laminar Natural Convection Boundary Layer Flow around a Vertical Heated Curvilinear Surface. International Journal of Applied Mathematics and Statistics, 30, 1-15.

[14] Vajravelu, K., Prasad, K.V. and Ng, C.-O. (2013) Unsteady Convective Boundary Layer Flow of a Viscous Fluid at a Vertical Surface with Variable Fluid Properties. Nonlinear Analysis: Real World Applications, 14, 455-464. https://doi.org/10.1016/j.nonrwa.2012.07.008

[15] Singh, G. and Sharma, P.R. (2014) Heat and Mass Transfer in the Boundary Layer Flow along a Vertical Isothermal Reactive Plate near Stagnation Point. Journal of Applied Fluid Mechanics, 7, 25-33.

[16] Ali, M.Y., Uddin, M.N., Uddin, M.J. and Zahed, N.M.R. (2015) Similarity Solutions of Unsteady Convective Boundary Layer Flow along Isothermal Vertical Plate with Porous Medium. Open Journal of Fluid Dynamics, 5, 391-406. https://doi.org/10.4236/ojfd.2015.54038

[17] Ali1, M.Y., Zahed, N.M.R., Uddin, M.N. and Uddin, M.J. (2016) Similarity Solutions for an Internal Heat Generation, Thermal Radiation and Free Convection Unsteady Boundary Layer Flow over a Vertical Plate. Journal of Scientific Research, 8, 341-353 https://doi.org/10.3329/jsr.v8i3.27851 
[18] Ali1, M.Y., Uddin, M.J., Uddin, M.N. and Zahed, N.M.R. (2016) Similarity Solutions for Unsteady Hydromagnetic Free Convection Boundary Layer Flow over Flat Plates with Thermophoresis. Journal of Scientific Research, 8, 287-307.

https://doi.org/10.3329/jsr.v8i3.27347

Submit or recommend next manuscript to SCIRP and we will provide best service for you:

Accepting pre-submission inquiries through Email, Facebook, LinkedIn, Twitter, etc.

A wide selection of journals (inclusive of 9 subjects, more than 200 journals)

Providing 24-hour high-quality service

User-friendly online submission system

Fair and swift peer-review system

Efficient typesetting and proofreading procedure

Display of the result of downloads and visits, as well as the number of cited articles

Maximum dissemination of your research work

Submit your manuscript at: http://papersubmission.scirp.org/

Or contactojfd@scirp.org 